LA-8261-MS

Informal Report

\title{
MASTER
}

\section{A Zero Dimensional Plasma Model and the Study of the Initial Performance of the ZT-40 Experiment}

世

$\frac{7}{\omega}$

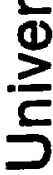

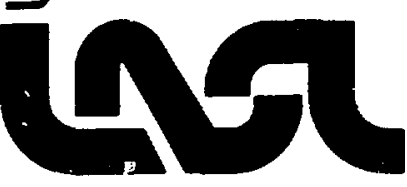


LA-8261-MS

Informal Report

UC-20f

Issued: February 1980

\title{
A Zero Dimensional Plasma Model and the Study of the Initial Performance of the ZT-40 Experiment
}

\author{
S. Ortolani*
}

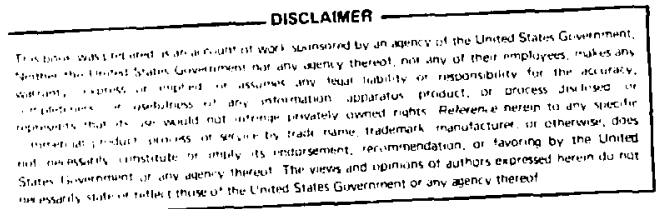

* LASL Consultant. Present address: Centro di Studio sui Gas lonizzati, CNR-Universitá di Padova, Associazione Euratom-CNR , Padova, ITALY.

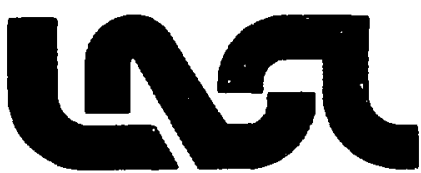


A ZERO DIMENSIONAL PLASMA MODEL AND THE STUDY OF THE INITIAL PERFORMANCE OF THE ZT-40 EXPERIMENT

by

S. ORTOLANI

\begin{abstract}
A plasma zero-dimensional model is described and some results obtained to study the initial performance of the $2 \mathrm{~T}-40$ experiment are discussed.
\end{abstract}

\title{
I . INTRODUCTION
}

The Initial performance of the $2 T-40$ experiment has been studied by a zero-dimensional plasma model. A computer code [ZCODEX] has been written on the PDP-10 to solve the equations of the model. The code has been written by adding other equations and terms to the OXYALU code developed by $F$. Jahoda and which is described in the note enclosed here as Appendix I.

This report summarizes the main features of the model, describes some aspects of how to use the code and briefly discusses some results obtained in simulating the 2T-40 experimental performance. The model is essentially an extension of the time dependent impurity radiation calculations described elsewhere. 1,2 The code written on the PDP-10 is similar to the one written in Padua on the IBM computer using the CSMP package. 3 The model has been applied to many experiments such as ETA-BETA $I^{4,5}$ and ETA-BETA II, 6,7,8 HBTX-1A, RFX and ZETA, $^{9}$ as well as to reactor calculations. 10 


\section{I'T. BASIC EQUATIONS}

The equations solved in the code are 1isted below:

electron energy equation:

$$
\begin{aligned}
& \frac{d}{d t}\left(\frac{3}{2} n_{e^{k} T_{e}}\right)=\text { POHM }- \text { PEQ,EI }- \text { PLR, OX }- \text { PLR,AL }- \text { PBREM } \\
& \text { - PRAD, FE - PION,D - PION,OX - PION, AL }
\end{aligned}
$$

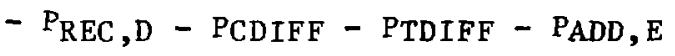

ion energy equation:

$$
\frac{d}{d t}\left(\begin{array}{ll}
3 \\
2 & n_{i k T I}
\end{array}\right)=P E Q, E I-P A D D, I
$$

ionization rate equation for the main filling gas $\left(D_{2}\right)$

$$
\frac{d}{d t} n_{e, D}=\left(n_{F}-n_{e}, D\right) n_{e} S_{D}-n_{e}, n_{e} \propto d
$$

where $n_{F}$ is the filling density of neutral atoms.

oxygen ions rate equations

$\frac{d n_{0 \times i}}{d t}=n_{0 \times}(i-1) S(i-1)-\left(n_{0 \times 1}\right)\left(s_{1}+\alpha_{i}\right)+n_{0 x}(i+1) \alpha_{i+1}$

$$
\text { with } i=1, \ldots, 9 ; n_{\text {oxo }}=n_{\text {oxl }} 5 \equiv 0 \text { and } \sum_{1}^{9} n_{o x i}=n_{\text {oxygen }}
$$


aluminum tons rate equations

$\frac{d n_{A 11}}{d t}=n_{A 1(1-1)} s_{1-1}-n_{A 11}\left(s_{i}+\alpha_{i}\right)+n_{A l}(i+1) \alpha_{i+1}$

with $1=1, \ldots, 14 ; n_{A 10}=n_{A 115} \equiv 0$ and $\sum_{1}^{14} n_{A 11}=n_{a 1 \text { um } 1 \text { num }}$

circuit equation

$\frac{d}{d t} Q=I$

$\frac{d I}{d t}=\frac{1}{L_{E}+L_{P}+I \frac{d L_{P}}{d I}} \cdot\left[V_{C O}-\frac{Q}{C}-\left(R_{E}+R_{P}\right) I\right]$

where $V_{C O}$ is the capacitor charging voltage at $t=0$, and the other symbols of the circuit which is drawn in Fig. 1 are discussed in the next section.

\section{DISCUSSION OF THE VARIOUS TERMS}

The Ionization, $S$, and recombination, $\alpha$, rate coefficients; the terms describing the electron-ion equipartition, $P_{E Q}, E I$ and the oxygen and aluminum line radiation powers, $P_{L R}, O X$ and $P L R, A L$ are equal to those described in Appendix $I$ and here only the new terms and equations are discussed. $P_{O H M}$ as in Appendix I, represents the ohmic heating power and is computed by assuming classical (Spitzer) parallel resistivity (including the $z_{\text {eff }}$ factor calculated self-consistently with the impurity ion distribution). However, here it is multiplied by a form factor to effectively account for the resistance change when a current distribution is actually present. The resistance form factor considered in the model $11,3,9$ is given by the following expression:

$$
F(\theta)=\theta / J_{1}(2 \theta) \quad \text { for } 0<\theta<1.46
$$


and is $F(0)=1$, and $F(\theta)=4$ for $\theta \geqslant 1.46$ where $\theta$ is the pinch parameter $\theta=$ $\mu_{\mathrm{oI}} / 2 \pi a B_{z o}$ where $a$ is the minor radius of the plasma (vacuum wal1) and $B_{z o}$ is the average field, within the vacuum wall, assumed constant in time. $J_{1}$ is the first kind, first order Bessel function. $P_{O H M}$ is then computed multiplying the resistivity by the average current density ( $\left.I / \pi a^{2}\right)$ squared. PBREM represents the bremsstrahlung radiation of the electrons in the fleld of the deuterium, oxygen, and aluminum lons, and also appears in Appendix $I$. The contribution due to the iron impurity lons is accounted for directly in the iron radiation terms as discussed below.

$P_{L R}, F E$ represents the total radiation losses assoclated with iron lons including: bremsstrahlung, radiative and dielectronic recombination and line transitions. This radiation loss term is described in the code by using the steady state radiative cooling rates as computed by Post, et al. 12 Also the mean Ion charge $\langle\mathrm{Z}\rangle=\Sigma_{\mathrm{n}_{z}} \mathrm{Z} / \Sigma_{\mathrm{n}_{\mathrm{Z}}}$ and the mean square charge $\left\langle\mathrm{Z}^{2}\right\rangle=\Sigma_{\mathrm{n}_{Z}} \mathrm{Z}^{2} / \Sigma_{\mathrm{n}}$ are computed $^{12}$ to include the iron contribution to the total electron density and to the $Z_{\text {eff }}=\Sigma_{n_{z}} Z^{2} / \Sigma_{n_{z}} Z$ factor in the resistivity. Whereas the time dependent ionization history is Important for low $Z$ lons, the steady state approximation for the Iron ton populations seems reasonable, bestdes being more practical; the justiffcation being as follows: the rate of change of plasma temperature scales approximately as Pohm/ $\mathrm{W}_{\mathrm{p}} \sim \mathrm{T}^{-5 / 2}$. Therefore at the higher temperature at which the lon radlation peaks ( $\sim 100 \mathrm{eV})$ the 1onization distribution will be closer to steady state than at the oxygen radiation peak $(\sim 20 \mathrm{eV})$.

PION,D represents the Ionlzation losses associated with the lonization of the main fflling gas; the power per unit volume lost is geven by:

$$
\mathrm{P}_{\text {ION, }}=\mathrm{EION}\left(\mathrm{nF}-\mathrm{n}_{e, D}\right) \mathrm{n}_{\mathrm{e}} \mathrm{SD}_{\mathrm{D}}
$$

Being that the excitation coefficient (for the resonant transition) and the Ionization coefficlent are about equal, some line radiation loss from the rain gas is also accounted for by simply considering $E_{\text {ION }} \simeq 20 \mathrm{eV}$ simflarly to Ref. 13 and 14 .

PION,OX AND PION, AL represent the losses associated with the lonization of the oxygen and aluminum lons and are calculated similarly to $P_{I O N, D}$ by summing over all the lonization states. $P_{R E C, D}$ is the power lost through 
electron-ion recombination processes (the recombination with the impurity ions is neglected) and is written as:

$$
\mathrm{P}_{\mathrm{REC}, \mathrm{D}}=\frac{3}{2} \mathrm{kT} \mathrm{e}_{\mathrm{e}, \mathrm{D}}^{2} \alpha_{\mathrm{D}}
$$

Only the free energy of the electrons is lost in terms of the thermal energy Eq. (1). However, the bound energy is of course also radiated, but this energy has been lost during the ionization process which happens at a different rate (the ionization rate).

$\mathrm{P}_{\mathrm{CDIFF}}$ is a term accounting for the transport losses for a steady-state classical plasmal9 for which it results:

$\frac{3}{2} \frac{\mathrm{nkT}}{\tau_{\mathrm{E}}}=\frac{1}{2} \mathrm{P}_{\mathrm{OHM}}$

As long as $T_{e} \simeq T_{1}=T$, it does not matter if this term is included in the electron or ion energy equation. In practice it means that half of the instantaneous ohmic heating power is assumed to be lost through transport.

$P_{\text {TDIFF }}$ is a term attempting to account for enhanced transport losses associated with magnetic field fluctuations.15,16 Two expressions are considered: one in which the level of fluctuation is held constant and one in which it varies according to $\mathrm{s}_{\Theta}^{-1 / 2}, 18 \mathrm{~s}_{\theta}$ being the magnetic Reynold number defined as $s_{\theta}=\left(\mu_{0} / \rho\right)^{1 / 2}$ oa $B_{\theta}(a$,$) where \sigma$ is the electrical conductivity, $\rho$ is the mass density and $B_{\theta}(a)$ is the azlmuthal magnetic field at the plasma boundary $\left[B_{\theta}(a)=\mu_{0} I / 2 \pi a\right] . \quad P_{A D D}, E$ and $P_{A D D}, I$ as discussed in Appendix $I$ are additional phenomenological loss terms which require the specification of a time constant by the user and can account for other losses, e.g., transport losses described differently from the two terms discussed above.

Finally the simple circuit drawn in Fig. 1 is considered to describe the toroidal plasma current, where $C$ is the total capacity of the capacitor bank; $R_{E}$ and $L_{E}$ are external circuit resistance and inductance and $L_{p}$ and $R_{p}$ are variable plasma inductance and resistance. The magnetizing inductance is assumed to be sufficiently large $\left(\sim 10 \mathrm{~L}_{\mathrm{p}}\right)$ to be neglected and iron saturation 
effects are not considered. A simple single mesh circuit is appropriate to describe both the formation (current rise) phase and the post-crowbar (either active or passive) phase provided the circuit parameters $c, R_{E}$ and $L_{E}$ are appropriately changed when switching from the formation to the post crow-bar phase. Because the $2 T-40$ circuit could be changed in the future, e.g., when the power crow-bar circuit will be installed, it may be useful to specify that the present circuit parameters ${ }^{17}$ are assigned in the Subroutine CIRPAM, (see the code 1isting enclosed as Appendix II) and can be easily changed. In the subroutine $G$, which builds the differential equations for integration, the crow-bar is applied at the specified time (input parameters) or in any case at zero bank voltage and the external circult parameters are changed as appropriate to the crow-barred circuit ${ }^{17}$ (see statements $741-751$ of the code). This part of the code can also be easily changed to include the power crow-bar circuit parameters, etc. The plasma resistance is given by $R_{p}=\eta L / S$ where $n$ is the plasma resistivity discussed above including the form factor, $L$ is the length of the plasma ( $2 \pi R$, with $R$ being the torus major radius) and $S$ is the plasma cross section $\left(\pi a^{2}\right)$.

The plasma inductance is modeled in agreement to what is discussed in Ref. 7 and is written as

$$
\begin{aligned}
& \mathrm{L}_{\mathrm{p}}=\frac{1}{2} \mathrm{~L}_{\mathrm{o}} \text { for } \theta<0.4 \\
& \mathrm{~L}_{\mathrm{p}}=\frac{3}{2} \mathrm{~L}_{\mathrm{o}} \text { for } \theta>1.5
\end{aligned}
$$

and

$$
L_{p}=\frac{1}{2} L_{p_{0}}\{2.3-1.3 \cos [\pi 0.625(\theta-0.4)]\}
$$

$$
\text { for } 0.4<\theta<1.5
$$


with

$$
L p_{0}=\frac{\mu_{0}}{2} R ; \text { with } R \text { being the torus major radius. }
$$

This model allows one to describe the $\mathrm{I} \mathrm{dLp} / \mathrm{dt}$ term which is important during the formation phase. A simpler constant inductance model can be appropriate if the final energy balance is of interest more than the time evolution. By assigning a very large bias field, $\mathrm{Bz}_{\mathrm{O}}$, the user can exclude the effect of the form factors both in the resistance and in the inductance automatically, by forcing $\theta \sim 0 . \quad \mathrm{Lp}_{\mathrm{o}}$ is defined in the same subroutine CIRPAM discussed above and if a $\theta \sim 0$ (no time variable form factor) case is of interest, the constant $L p_{0}$ value should be changed as well to represent the final value corresponding to the end of the current rise phase; this can be done in the CIRPAM subroutine of the code by using the variable FACTOR.

\section{THE CODE}

A listing of the code is enclosed for refarence in Appendix II and three sample printouts are enclosed in Appendix IV. The execution of the code is obtained by the command file: EX \& ZCODEX.CMD which is very similar to the file IMPUR.CMD described in Appendix I with only the addition of the IMSL library which is accessed to compute the Bessel function $J_{1}$. The input dialog Is easily Interpretable (an example is reported in Appendix III). It is worthwhile only to specify that the transformer ratio is intended to be the primary to secondary turn ratio $(0.25$ presently on $2 \mathrm{~T}-40)$ and that three printouts (see Appendix IV) are avallable; all three eventually give the plots of the electron temperature and the plasma current, but each individually prints details of the impurity ion distribution or of the circuit quantities or of the flux and energy balance respectively.

The user is asked to provide values for various switches which allow selection of the type of printout, the inclusion or not of transport losses, etc....

It should also be noted that the time integrals to obtain the various Elux and energy terms are performed for simplicity on timesteps equal to the printout timesteps; so exact balance cannot be presumed unless reasonably 
small steps (much less than the current rise time) are prescribed by the user. Also because the circuit parameters are changed after the crow-bar, the magnetic energy present in the circuit portion from the bank to the crow-bar, just before the crow-bar time, must be added to get, after the crow-bar time, total energy conservation.

\section{ZT-40 INITIAL PERFORMANCE}

An important step in the performance of any magnetic confinement experiment is to overcome the line radiation losses due to the presence of light elements $(\mathrm{C}, \mathrm{N}, \mathrm{0..)})$ as impurities in the plasma. The model has therefore been applied to study the effect of the radiation losses associated with oxygen impurities on the initial performance of the $2 \mathrm{~T}-40$ experiment. In Fig. 2 is drawn the time for the plasma current to decrease to $1 /$ e of the peak value versus the deuterium filling density for various concentrations of oxygen impurity lons as computed by the model discussed above. For these runs only the ionization and recombination losses of the main gas, the bremsstrahlung radiation and the so-called classical diffusion losses are included besides the oxygen line radiation which by far is the dominant effect. The calculations indicate that before encountering the circuit limit for the current decay time, due to the relatively high external circuit resistance, the behaviour is dominated by the plasma resistance at the higher filiting pressures considered (5-10 mtorr) even tf only $1 \%$ of 2 mtorr (1.4 $10^{12} \mathrm{~cm}^{-3}$ ) oxygen impurity ions are present. The results shown in Fig. 2 are for a bank voltage of $6 \mathrm{kV}$ corresponding to $\sim 370 \mathrm{kA}$ plasma current (the peak current obtained actually varies $\sim 10 \%$ going from 10 to 2 mtorr). The experimental results obtained with comparable conditions are also shown Indicating that an oxygen concentration between 3.5 and $7 \cdot 10^{12} \mathrm{~cm}^{-3}$ could expiain the observed independence of the current decay time on the filling pressure unless other phenomena dominate. The computed electron temperatures at the time of current peak are drawn in Fig. 3 indicating that the observed current decay times are consistent with average temperatures of the order of $10 \mathrm{eV}$ but that substantially higher temperatures could be reached when burning through the oxygen impurities occurs. The calculations have been performed also at 8 and $10 \mathrm{kV}$ bank voltage for both 3.5 and $7 \cdot 10^{12} \mathrm{~cm}^{-3}$ oxygen impurity concentration. The results for the current decay time and for the temperature reached at peak current are shown in Figs. 4 and 5 . Eventually by operating 
at $10 \mathrm{kV}$ even $7 \cdot 10^{12} \mathrm{~cm}^{-3}$ oxygen impurity should not prevent to extend the plasma lifetime up to the limit imposed by the present circuit, provided the operating pressure is at 2-3 mtorr.

A comparison between the computed and the measured variation of the current decay time and amplitude versus the bank charging voltage is shown in Figs. 6 and 7. As examples of the sort of agreement which is obtained between the measured and computed plasma current the two curves have been drawn in Figs. 8 and 9 for a 10 mtorr and a 2 mtorr discharge respectively. Examples of the computed oxygen Ion populations versus time are shown in Fig. 10 (a and b) and this behaviour could be compared with experimentally measured line intensities versus time and with temperature measurements, to study the consistency of various independent measurements. Finally an example of the volt-seconds consumption and of the time dependence of the various terms of the energy balance is shown in Fig. 11 ( $a$ and $b$ ) and the time evolution for the plasma current and electron temperature 1s drawn in Fig. 12. It is seen how the temperature is held down during the lonization growth (first 20 Hs) and subsequently increases up to $\sim 20 \mathrm{eV}$ but the oxygen radiation barrier is not quite overcome in the example and the temperature falls rapidly after the crow-bar and so does the current.

\section{REFERENCES}

1. S. Costa and S. Ortolani, "Study of the Impurity Radiation Losses in a Pinch Discharge," University of Padua report, UPee 75/06, 1975.

2. D. A. Baker, L. C. Burkhardt, J. N. DiMarco, A. Haberstich, R. B. Howe1l, J. H. Karr, S. Ortolani, A. E. Schofield, "Toroidal Reverse Field Pinch," Section VI in CTR Annual Report 1975, LA-6582-PR, 1976.

3. M. Bagatin, S. Costa, S. Ortolani, and A. Stella, to be published.

4. A. Buffa and S. Ortolani, "Ionization and Start-up Problems in ETA-BETA I with the 100 us Rise Time," internal note G.I.P. 78-14, contribution to the "RFP Workshop," Padova, Sept. 1978.

5. M. Bagatin A. Buffa, R. De Angelis, G. Malesani, S. Ortolani, "Studies on Plasma Formation, Relaxation, and Heating in a Reverse Field Pinch," 7 th International Conference on Plasma Physics and Controlled Nuclear Fusion Research, IAEA-CN-37/E-13, Innsbruck, Austria, 1978.

6. S. Ortolani, "Performance e impurita in ETA-BETA II," internal note G.I.P. 78-02, 1978. 
7. S. Ortolani and A. Stella, "A Zero-Dimensional P1asma Model-Calculations on ETA-BETA II with Various Current Rise Times," internal note G.I.P. 78-16, contribution to the "RFP Workshop" Padova, Sept. 1978.

8. A. Buffa, S. Costa, R. De Angelis, J. N. DiMarco, L. Giudicotti, G. Malesani, G. Nalesso, S. Ortolani, and P. Scarin, "First Results from the ETA-BETA II RFP experiment," 9 th European Conference on Controlled Fusion and Plasma Physics, Oxford, England, 1979.

9. M. Bagatin, P. G. Carolan, S. Ortolani, I. Piotrovich, A. Stella, M. R. C. Watts, to be published.

10. M. Bagatin and S, Ortolani, "Zero-Dimensional Calculations on the Start-up and Heating of a RFP reactor," internal note G.I.P. 78-17, contribution to the "RFP Workshop," Padova, Sept. 1978.

11. D. C. Robinson, Culham Laboratory, private communication, 1977 .

12. D. E. Post, R. V. Jensen, C. B. Tarter, W. H. Grasberger, W. A. Lokke, "Steady-State Radiative Cooling Rates for Low Density, High Temperature Plasma, Atomic Data and Nuclear Tables," Voi. 10, No. 5, Nov. 1977.

13. R. Papoular, "The Genests uf Toroidal Dischazges," Nucl. Fusion 16, 1, $37,1976$.

14. R. J. Hawryluk, and J. A. Schmidt, "Effects of Low $Z$ Impurities during the Start-up Phase of a Large Tokamak," iJucl. Fusion 16, 5, 775, 1976.

15. D. C. Robinson, "The Effect on Confinement of an Unstable Central Region in a Reverse Field Pinch," 3rd Top. Conf. Pulsed High Beta Plasmas, Culham, B1.7, 1975.

16. S. Ortolani, "Fluttuazioni magnetiche e perdite di energia," internal note, G.I.P. 78-03, 1978 .

17. R. Gribble, Los Alamos Sclentific Laboratory, private communication, October 1979.

18. C. W. Gowers, S. Ortolani, D. C. Robinson, M. R. C. Watts, "Residual Instabilities in Reverse Field Pinches produced on HBTX1, "19th Annual Meet. Am. Phys. Soc., Div. P1. Phys., At1anta, 1977

19. S. Ortolani, "Simple Thoughts on the Parameters of a P.0.P. RFP experiment," internal note, G.I.P. 78-20, 1978. 


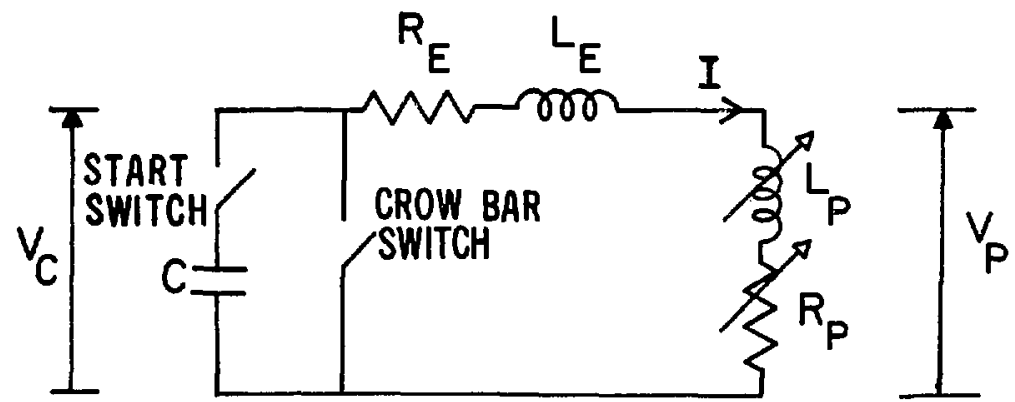

Fig. 1. Toroidal current equivalent circuit. 


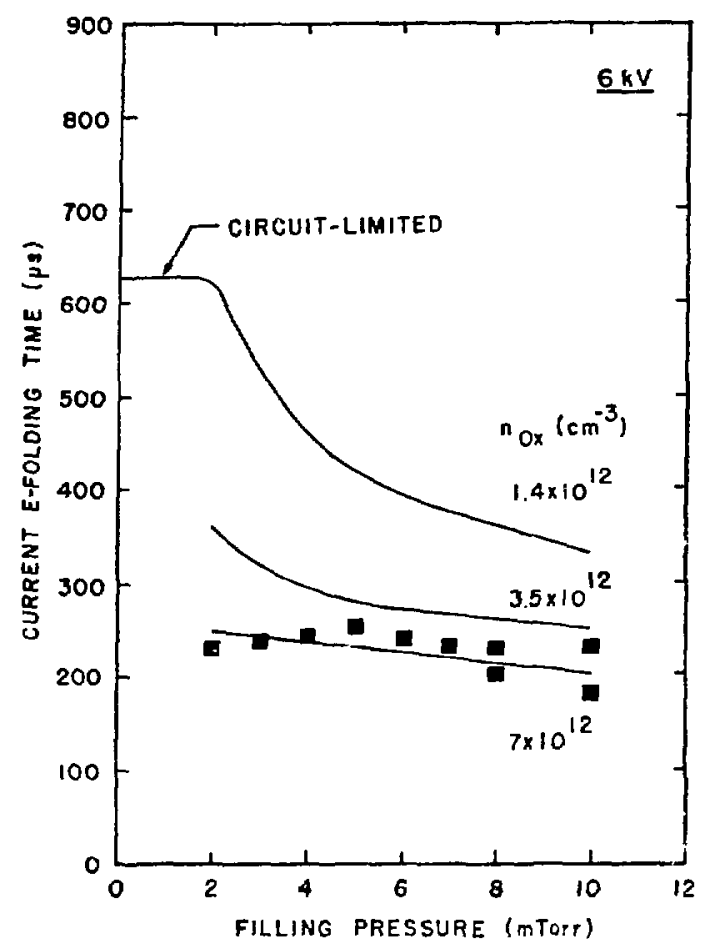

Fig. 2. Time for the current to decrease to $1 / \mathrm{e}$ of the peak value versus the filling pressure. The solid curves are computed and the $\square$ are measured values.

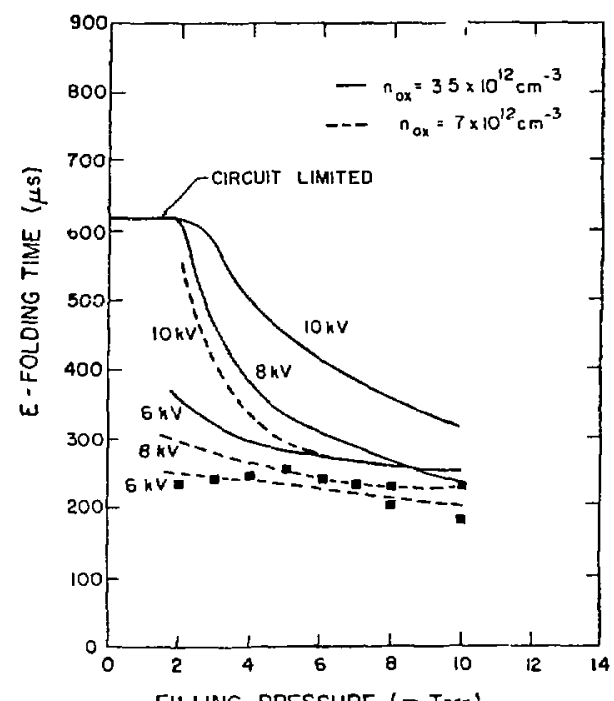

FILUNG PRESSURE ( $m$ Torr)

Fig. 4. Time for the current to decrease to $1 / \mathrm{e}$ of the peak value versus the filling pressure. The curves are computed and the $\square$ are measured values.

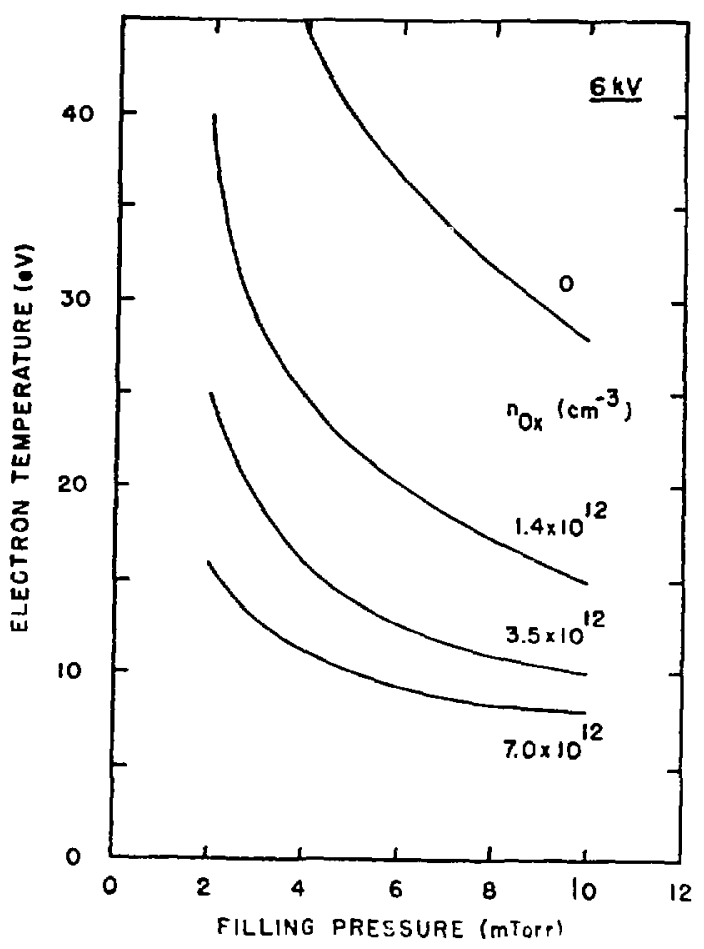

Fig. 3. Computed variation of the electron temperature at the time of current peak versus the filling presslire.

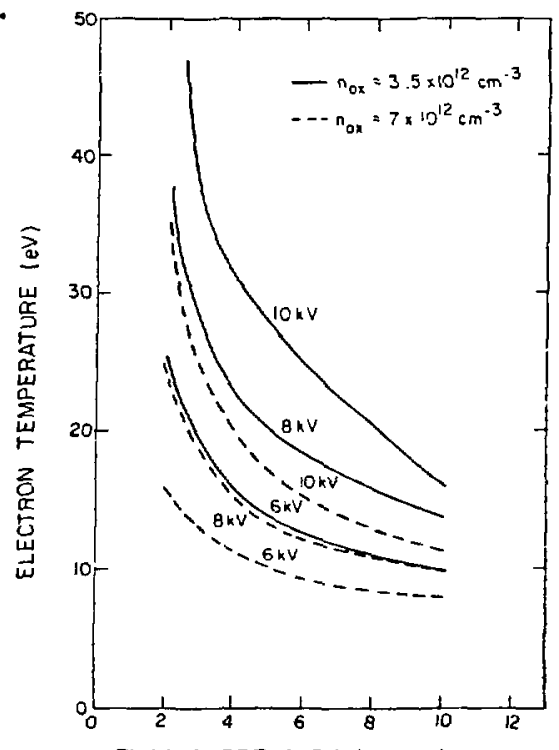

FILLING PRESSURE ( $m$ TOIP)

Fig. 5. Computed variation of the electron temperature at the time of current peak versus the filling pressure. 


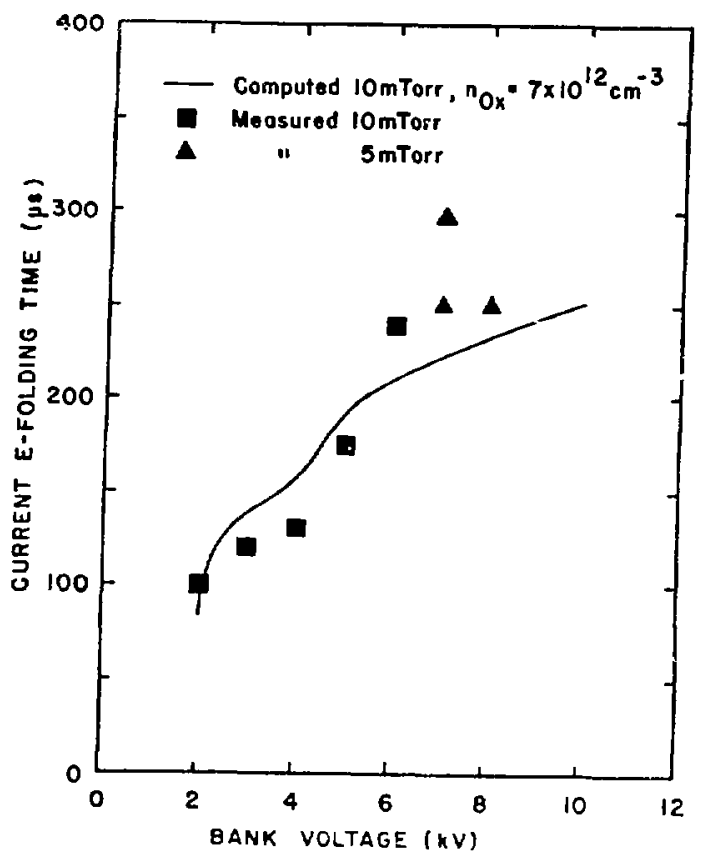

Fig. 6. Computed and measured current decay times versus the applied bank voltage.

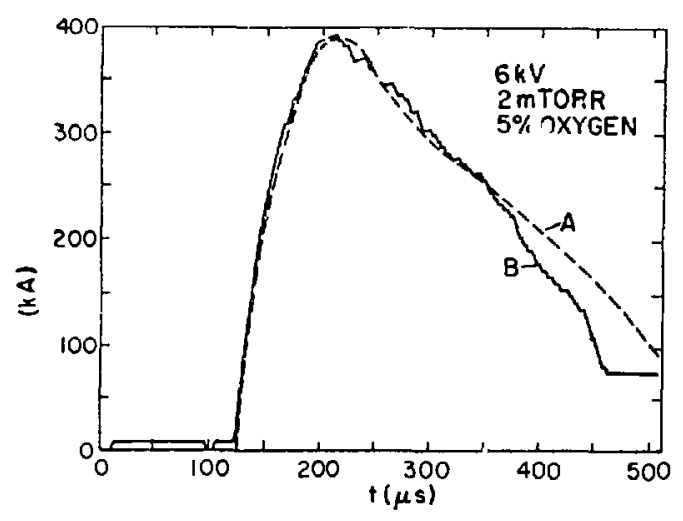

Fig. 8. Computed and measured current vs time. $A=$ computed, $B=$ measured.

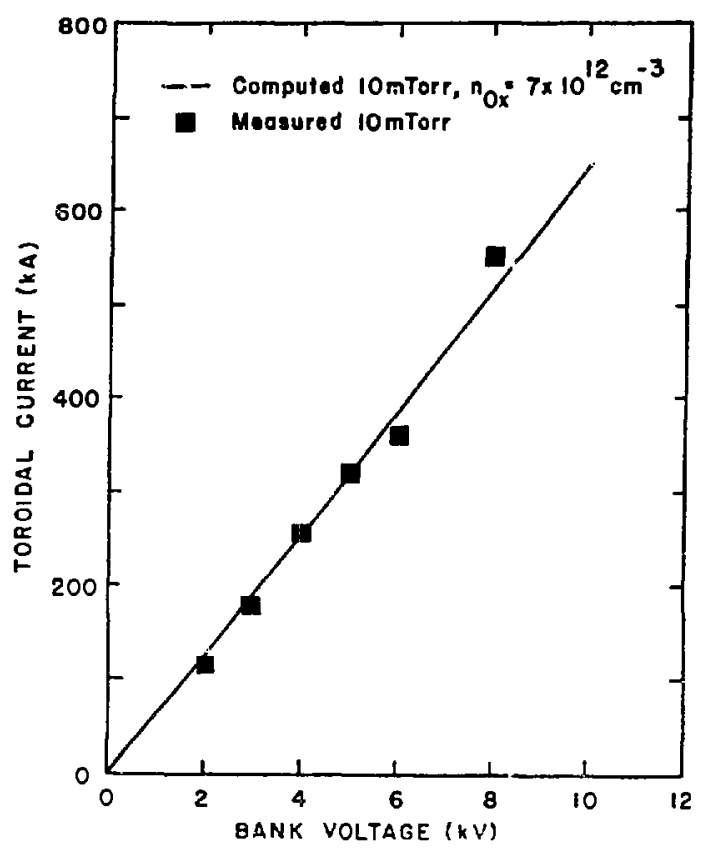

Fig. 7. Computed and measured current peak amplitude versus the applied bank voltage.

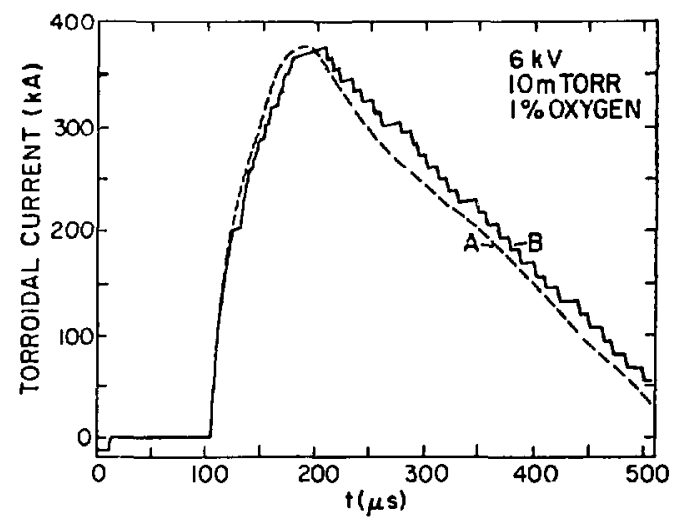

Fig. 9. Computed and measured current vs time. $\mathrm{A}=$ computed, $\mathrm{B}=$ measured. 

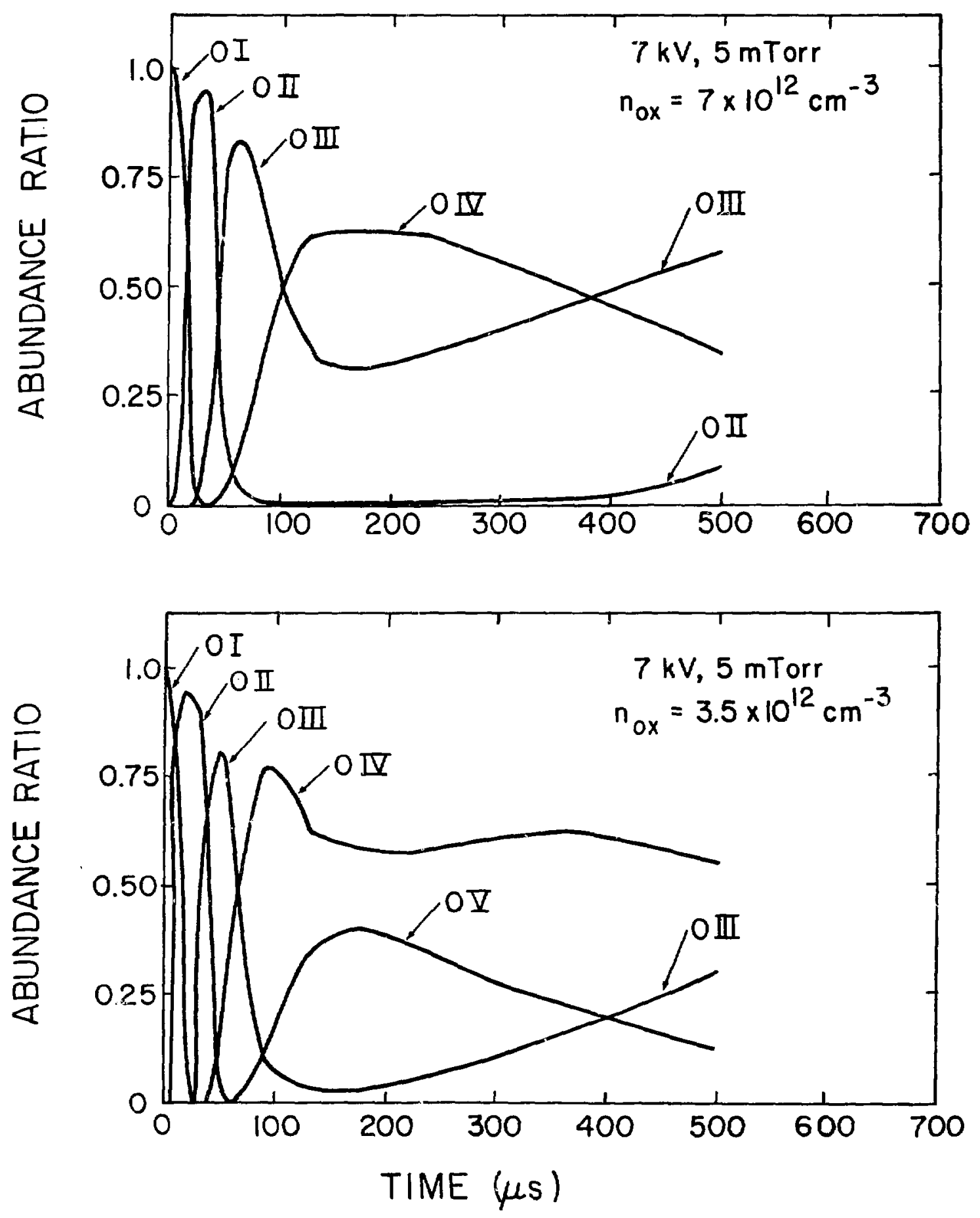

Fig. 10. ( $a$ and b) Fractional abundances of the oxygen ions versus time. 


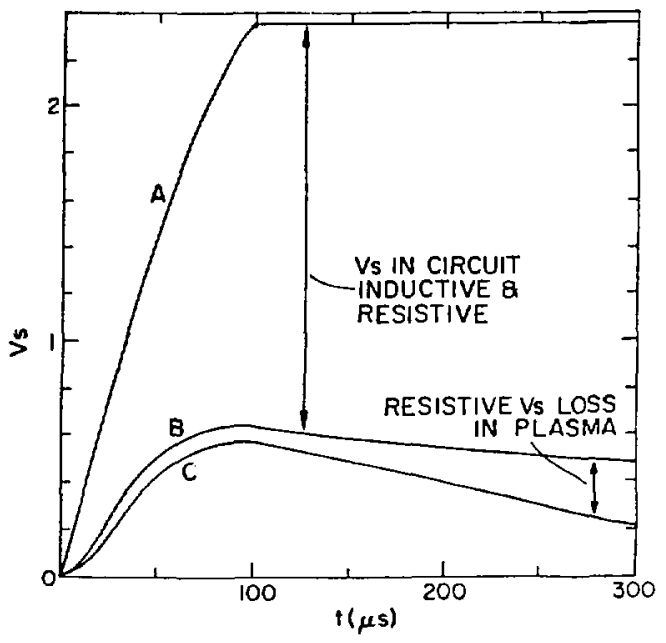

Fig. 11. ZT-40 Run:

Fig. 11a. Volt seconds consumption

$$
\begin{aligned}
A= & \text { Vs generated }=\int V_{c} d t \\
B= & V s \text { applied to the } \\
& \text { plasma }=\int V_{p} d t \\
C= & \text { poloidal } f 1 l x \text { in the } \\
& \text { plasma }=L_{p} I
\end{aligned}
$$

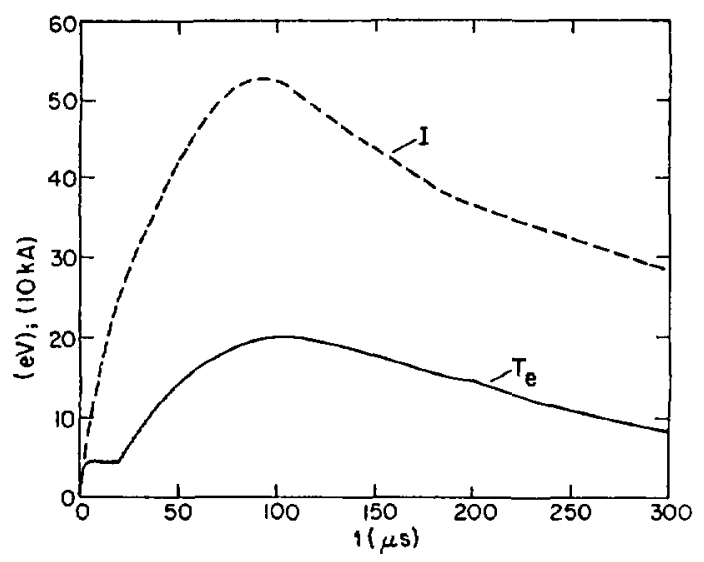

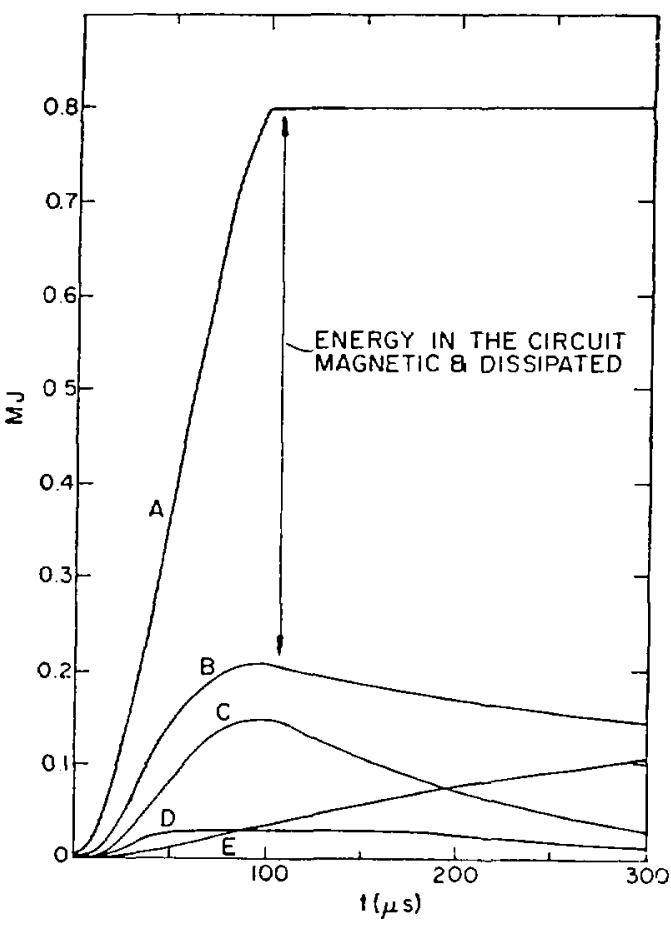

Filling pressure $=5$ mtorr

Toroidal current bank voltage $=8 \mathrm{kV}$ Oxygen impurity $=1 \%$

Fig. 11b. Energy balance

$$
\begin{aligned}
\mathrm{A}= & \text { energy generated }=\int \mathrm{V}_{\mathrm{c}} \mathrm{Idt} \\
\mathrm{B}= & \text { energy input to the } \\
& \text { plasma }=\int \mathrm{V} I d t \\
\mathrm{C}= & \text { magnetic energy in the } \\
& \text { plasma }=\frac{1}{2} \mathrm{~L} \mathrm{I}^{2} \\
\mathrm{D}= & \text { energy assogiated with } \\
& \text { the inductance varia- } \\
& \text { tion }=\frac{1}{2} \int \mathrm{I}^{2} \mathrm{dL} \\
\mathrm{E}= & \text { energy dissipgted in the } \\
& \text { plasma }=\int \mathrm{R}_{\mathrm{p}} \mathrm{I}^{2} \mathrm{dt}
\end{aligned}
$$

Fig.11c. Computed plasma current and electron temperature versus time. 


\section{INTRODUCTION}

This report describes the computer code OXYALU, as implemented on the PDP-10. It calculates the temporal temperature behavior of an ohmically heated uniform plasma as a function of oxygen and aluminum impurity concentrations. These are chosen as the most likely dominant low $\mathrm{Z}$ impuritles, and serve as prototypes for other low $Z$ impurities. Since no detailed spectral results are derived, generally a single impu:ity element approximation is sufficient. The following description refers only to oxygen, though as just stated, the actual code handles aluminum as well.

The heart of the calculation is a solution of the time dependent differential equation for electron energy, which is symbolically written as Eollows:

$$
\begin{aligned}
& \frac{d}{d t}\left(\frac{3}{2} n k T_{e}\right)=\text { ohmic heating } \pm \text { ion-electron equilibriation - oxygen } \\
& \text { line radiation - continuum radiation - additional loss cerms }
\end{aligned}
$$

The second term on the right may be plus or minus diending on the (time-dependent) Instantaneous ion temperature. It requires simultaneous solution of a second differential equation for ion energy.

The third term is a summation over the line radiation from each separate ionization stage of oxygen. The approximation for the line radiation from each ionization stage is described later. It depends linearly on the ground-state population of each stage. Given the total oxygen impurity content and the initial distribution of ionization stages, it requires nine additional simultaneous differential equations to determine the time dependent ground state populations. These equations involve temperature dependent Ionizatior rate coefficients and temperature and density dependent 
recombination rate coefficients. The generation of these rate coefficients and the solution of the lonization stage distribution comprise the major numerical tasks of the program. (Radiation losses are generally high for lower lonization stages and the energy loss rates during the approach to steady state are of primary 1nterest. For this reason the assumption of instantaneous adjustment of ionization to steady state values is Inadmissible.)

The fourth term on the right is the calculated bremsstrahlung and recombination radiation for both deuterium and the oxygen impurity. In general the 1mpurity line radiation is more 1mportant but this term puts an upper limit on the attalnable temperature for any amount (including zero) of 1mpurity content.

The fifth term on the right is strictly phenomenological, requiring only specification of a time constant by the user, to accourit for extraneous loss terms, e.g., transport, that one may wish to approximate. A similar tarm with 1ndependent choice of time constant appears in the ion equation.

In summary, the code solves an Initlal value problem for 11 simultanrous differential equations.

$$
\begin{aligned}
& (1)--(9): \\
& \frac{d n_{1}}{d t}=n_{1-1} S_{i-1}\left(T_{e}\right)-n_{i} s_{1}\left(T_{e}\right)-n_{1} \alpha_{1}\left(T_{e}, n_{e}\right)+n_{1+1} \alpha_{1+1}\left(T_{e}, n_{e}\right) \\
& 1=1, \ldots, 9 \quad \mathrm{n}_{0}=\mathrm{n}_{10} \equiv 0 \quad \sum_{1}^{9} \mathrm{n}_{1}=\mathrm{n}_{\text {oxygen }} \\
& \text { (10): } \frac{3}{2} \mathrm{nk} \frac{\mathrm{dT}_{1 \text { in }}}{\mathrm{dt}}=\mathrm{f}\left(\mathrm{T}_{\mathrm{e}}-\mathrm{T}_{1 \text { on }}\right)-\frac{3}{2} \mathrm{nk} \frac{\mathrm{T}_{\text {1on }}}{\tau_{\text {1on }}} \\
& \text { (11): } \frac{3}{2} \text { nk } \frac{\mathrm{dT}_{e}}{\mathrm{dt}}=\text { ohmic heating }-\mathrm{f}\left(\mathrm{T}_{\mathrm{e}}-\mathrm{T}_{\text {ion }}\right)-\text { I1ne radiation } \\
& \text { - continuum radiation }-\frac{3}{2} \text { nk } \frac{\mathrm{T}_{\mathrm{e}}}{\tau_{\mathrm{e}}} \text {. }
\end{aligned}
$$


The 11 time dependent variables, each given an inttial value, are $n_{1}=1$, - ., 9, $\mathrm{T}_{\text {ion }}, \mathrm{T}_{\mathrm{e}}$. Specif led parameters are $\mathrm{n}_{\mathrm{e}}, \mathrm{n}_{\text {oxygen }}, \mathrm{J}(\mathrm{t}), \tau_{e}, \tau_{10 n}$, with

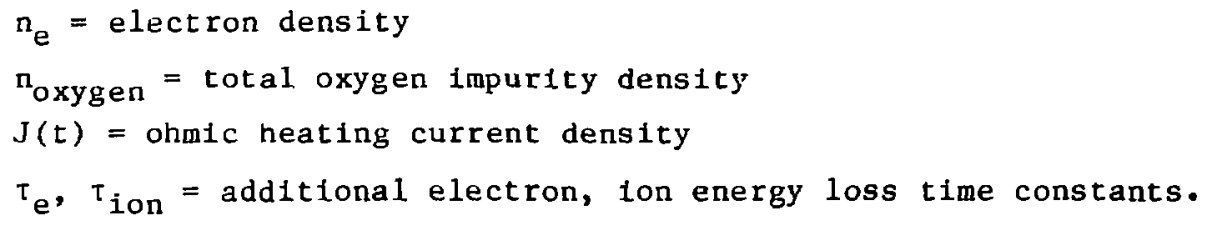
respectively. The time dependences of $J(t)$ is given by a simple analytical function.

The next section discusses the physics input and approximations for the calculation. The final section describes the program code organization.

\section{PHYSICS}

\section{A. Ionization and Recombination Rate Coefficients}

The Ionization and recombination rate coefficients are taken from the 1974 Appleton Laboratory Report by Hugh P. Summers, "Tables and Graphs of Collisional Dielectronic Recombination and Ionization Coefficients of H*like to A-like Ions of Elements." A more accessible description of the rather sophisticated physical processes taken into account appears in Summers, Monthly Notices of Royal Astro. Soc. 169, 663-680 (1974). A private communication from R. W. P. McWhirter (Nov. 1978) indicated that tnis 1s still the best available source.

\section{B. Impurtity Line Radiation}

The model assumes that all impurity line radlation results from radiative decay following collisional excltation of the ground state of the various Ionization levels. Following R. W. P. McWhirter for the radiated power loss due to the resonance line of an ion in a corona model plasma (Eq. (96), p. 243 in Plasma Diagnostic Techniques, Academic Press, 1965, R. H. Huddlestone and S. L. Leonard, Eds.), 


$$
\begin{gathered}
P=n_{e^{n}} \frac{5.44 \times 10^{-16_{f}}}{T_{e}^{1 / 2}} \exp \left(-\frac{1.16 \times 10^{4} E}{T_{e}}\right) \text { erg } \mathrm{cm}^{-3} \sec ^{-1} \\
T_{e} \text { in }{ }^{\circ} K
\end{gathered}
$$

or

$$
P=n_{e^{n}} \frac{5.05 \times 10^{-18} f}{T_{e}^{1 / 2}} \exp \left(-\frac{E}{T_{e}}\right) \operatorname{erg~} \mathrm{cm}^{-3} \sec ^{-1}
$$

$\mathrm{T}_{\mathrm{e}}$ in eV

In these equations $f$ and $E$ are the osclllator strength and excitation potential of the individual resonance lines, respectively. For the computer code two "averaged" resonance lines per ionization stage are used, with average $f$ and $E$ values taken from calculations of Group T-4, courtesy Al Merts. The actual values used can be gotten from the program listing at the beginning of Subroutine FSETUP, OS(1,1) through oS $(8,2)$ for oscillator strengths and $\mathrm{DE}(1,1)$ through $\mathrm{DE}(8,2)$ for averaged excitation potentials.

In addition, an empirical correction factor multiplier (=5) was originally put into the calculation in an attempt to approximate better more recent detalled calculations on 1ndividual lines and fragmentary experimental results, based on private communications from the University of Maryland. Subsequently an article by $H$. Griem on "Atomic Rate Coefficients for Tokamak Plasmas" has appeared in the Proceedings on Plasma-Wall Interactions, Jülich, West Germany, Oct. 1976, Comparison of the values giver there with those in the present code after inclusion of the factor 5, indicates that our values are about a factor 2 high (except for the lithium-like ion OVI, in which our value is about 50\% low). Since Griem is the world authority in this matter and also the source of the original factor 5, his values must be regarded as better. (In rereading McWhirter it appears he had already increased the Seaton estimate of effective Gaunt factor). However, the factor 5 has been retained for the following reason: uncertainties remain in what the best Seaton approximation is and the code should be on the conservative side, i.e., overestimate rather than underestimate the cooling effect of impurities. 
Furthermore, whenever heating dominates, changing the loss terms causes only small differences in the results. The results can be characterized as exhibiting a critical impurity concentration below which heating proceeds almost unimpeded and above which the temperature is clamped in a balance of heating and loss terms.

The actual value of $\mathrm{n}_{e}$ changes $\mathrm{in}$ time as the impurity content passes through successive ionfzation stages. This correction is included in the calculation.

\section{Continuum Radiation}

The continum radiation term consists of bremsstrahlung and recombination radiation for both the deuterium and the various oxygen ionization stages.

From, e.g., Glasstone and Lovberg, "Controlled Thermonuclear Reactions," Van Nostrand, 1960, Eq. 2.25, p. 31,

$$
\begin{aligned}
& P_{b r}=1.57 \times 10^{-27} n_{e^{\sum}\left(n_{i} z^{2}\right) T^{1 / 2}} \mathrm{ergs} / \mathrm{cm}^{-3} \mathrm{sec} \\
& \text { with } \mathrm{T}_{\mathrm{e}} \text { in }{ }^{\circ} \mathrm{K}
\end{aligned}
$$

while from Griem, Plasma Spectroscopy McGraw-Hill, 1964, p. 195, the recomination radiation can be approximated by a factor $x / k T$ larger than bremsstrahlung, where $x$ is the ionization potential of the recombined ion.

\section{Electron-Ion Ēullibration}

The electron-ion energy exchange term is taken from Eq. 9-60 in Longmire, "Elementary Plasma Physics," John Wiley and Sons, Inc.

$$
\frac{d\left(\frac{3}{2} \mathrm{nkT}_{\mathrm{e}}\right)}{d t}=\mathrm{n}_{\mathrm{e}^{n_{D}}} 4(2 \pi)^{1 / 2} \mathrm{e}^{4} \ln \Lambda \frac{\mathrm{m}_{\mathrm{e}^{1 / 2}\left(k \mathrm{~T}_{1}-k \mathrm{~T}_{\mathrm{e}}\right)}}{\mathrm{m}_{\mathrm{D}}\left(k \mathrm{kT}_{\mathrm{e}}\right)^{3 / 2}}
$$

Subscript $D$ refers to deuterium, and $\ln \Lambda$ is the Coulomb logarithm, where 


$$
\Lambda=\frac{3}{2 e^{3}}\left(\frac{k^{3} T^{3}}{\pi n e}\right)^{1 / 2} \text { for } T<4.2 \times 10^{5} o_{K}
$$

and multiplied by $\left(\frac{4.2 \times 10^{5}}{\mathrm{~T}}\right)^{1 / 2}$ when $\mathrm{T}>4.2 \times 10^{5} \mathrm{o}_{\mathrm{K}}$

(Spitzer, "Physics of Fully Ionized Gases," Interscience, 1962.)

The correction to the exchange term due to the impurity ions is small and has been ignored.

\section{E. Ohmic Heating}

Classical resistivity (F. Chen, "Introduction to Plasma Physics," Plenum Press, 1974) is given by

$$
\begin{aligned}
& \eta_{\|}=5.2 \times 10^{-3} z_{\text {eff }} \text { en } \Lambda / T^{3 / 2} \text { ohm-cm } \\
& \text { ( } \mathrm{T} \text { in } \mathrm{eV} \text { ) } \\
& z_{\text {eff }}=\frac{\Sigma_{z} n_{z} z^{2}}{\Sigma_{z} n_{z} z} \simeq 1+\frac{\Sigma_{i} z_{i}^{2}}{n_{e}}
\end{aligned}
$$

Energy eddition per unit volume is $\mathrm{nJ}^{2}$, in units of joules/m 3 sec if $n$ is ohm - m and $\mathrm{J} 1 \mathrm{~s}$ amps $/ \mathrm{m}^{2}$. For energy in units of ergs $/ \mathrm{cm}^{3}-\mathrm{sec}$ and $\mathrm{J}$ in $\mathrm{kA} / \mathrm{cm}^{2}$, proper unit conversion gives

$$
P_{\text {ohmic }}=5.2 \times 10^{10} \frac{Z_{\text {eff }} \ln \Lambda}{T_{\text {ev }}^{3 / 2}} \mathrm{~J}^{2} \quad \text { ergs } / \mathrm{cm}^{3}-\mathrm{sec}
$$




\section{F. Other Loss Processes}

As previously mentioned, time constants for additional arbitrary energy loss terms for both electrons and ions may be entered by the user.

\section{G. Mode1 Limitations}

Obviously, due to approximations and lack of precise knowledge of atomic rates and neglect of certain detail, the code results are indicative of trends rather thar accurate predictions. The biggest limitation is the assumption of spatial unfformity.

PROGRAM CODE

Execution proceeds via a command file

EX COXYALU.CMD (= EX OXYALU, RATESB, SUMMER, PUB:CTR6/LIB, PUB : PLOT $10 / L I B)$

where the file OXYALU is the main program described in this report and the file RATESB, which in turn calls SUMMER, is invoked only when the requested density differs from the density used during the last execution of the program, in order to compute a new table of recombination coefficients. OXYALU and RATESB themselves call files IONROA.DAT, RECSUM.DAT, and OA.DAT, containing ionization and recombination rates and the most recent density value, respectively, and which must originally have been copled into the user directory (once and for all). Each time new recombination coefficients are computed they are placed in a file called RATBO.DAT.

RATESB and SUMMER, themselves, are modifications of a general program, IONREC, written by Ed Fenimore, P-4, that generates the coefficients for many elements up to atomic number 30 from the Summers tables. (IONREC has been adapted to run on the PDP-10 and is also available. It was used also to generate the ionization rates in IONROA.DAT.).

During the intialization of every problem the coefficient tables are read (SUBROUTINE SETF) from IONROA.DAT and RATBO.DAT multiplied by $10^{-6}$ for conversion to $\mu \mathrm{sec}^{-1}$, and retained in a COMMON block location. (Two particular values are printed out as a diagnostic check that all the subsidiary files have been available and properly accessed.) 
Also during the initialization a call to SUBROUTINE FSETUP loads the oxygen lonization potentials, oscillator strengths, average resonance line excitation potentials, and a few constants that will be used in the energy equations.

The differential equation solver is the PDP-Public Library routine ODE, with equations set up in subroutine $G$. The differential equations themselves appear according to the terms described in the physics section above. Only five oxygen (and five aluminum) rate equations are used, picked automatically each new time cycle to be optimally centered about the ionization stages with maximum population. The constants follow from the fact that temperatures are now in units of ev, time is in microseconds, and all terms of the two energy equations have been divided by the factor $3 / 2 n k$, where $n$ is the density variable and $k$ is the Boltzmann constant $1.6 \times 10^{-12} \mathrm{ergs} / \mathrm{eV}$. The rate coeffictents are determined by linear interpolation (SUBROUTINE OXY) for current value of electron temperature from the tables.

Input is requested from the user in easily interpretable terminal dfalogie form. If a nonconstant ohmic heating current is chosen, a sinusoidal rise time $t_{r}$ and an exponential decay time $t_{d}$ are requested for the analytic expression $J=J_{\max } \sin \left(\pi / 2 t / t_{r}\right) \exp \left(-t / t_{d}\right)$ for $t<t_{r}$, and $J=J_{\max }$ $\exp \left(-t / t_{d}\right)$, for $t<t_{r}$.

Time steps for print-out also determine the time interval specified on each call to the differential equation solver routine. After the spacified total time is reached an option is given to extend the time with a new choice of time step. Experimentation with small initial steps, watching progress, is advised. The print-out gives time, $T_{i}$, relative population of oxygen and alumfnum fonization states, $T_{e}$, and a check-sum on relative populations that must remain very nearly equal to 1 . A plot request instead of a time extension ends the problem with an auto-scaled graph of electron and ion temperatures versus time with linear interpolation between all previously called-out time steps.

Two additional convenient features have been incorporated:

a) At the end of each run an cption may be exercised (up to 4 times total) to defer plotting, permitting multiple plots for purposes of comparison. All $\mathrm{T}_{\mathrm{e}}$ curves (up to 4) are plotted, but only the $\mathrm{T}_{\mathrm{i}}$ curve corresponding to the last case calculated is shown. The 
various curves can be identified from a legend identifying the various plotting characters, and all input parameters are printed out.

b) An additional option during the input dialogue can Include a linearly Increasing impurity content during a chosen time interval by specifying the desired time constant to double the initial impurity concentration. (This option is implemented for oxygen only, by the inclusion of a constant term on the right side of the lowest active oxygen ion rate equation.) Proper execution of this option can be monitored by observing if the check-sum on relative population Increases at the expected rate.

ACKNOWLEDGMENTS

A simple inttial version of this code was written by s. Ortolani. E. Fentmore provided his CCF code for rate coeffictents and helped with 1 ts conversion to PDP-10. A. Merts provided averaged oscillator strengths and energy levels. L. Mann has helped throughout the progressive code development. 
LASL Identification

No. LP-2050

\section{APPENDIX II.}

\section{LISTING OF THE CODE}

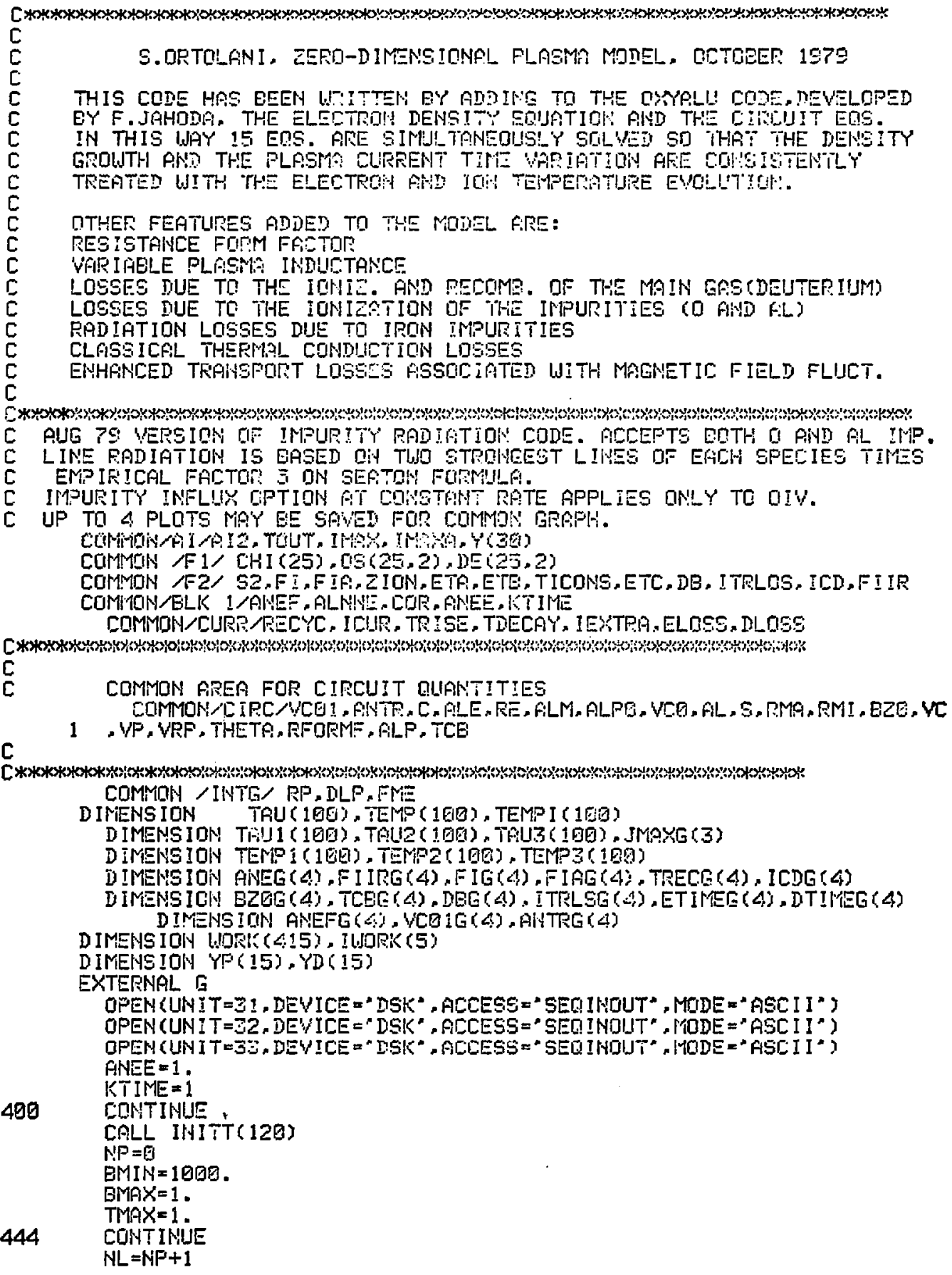




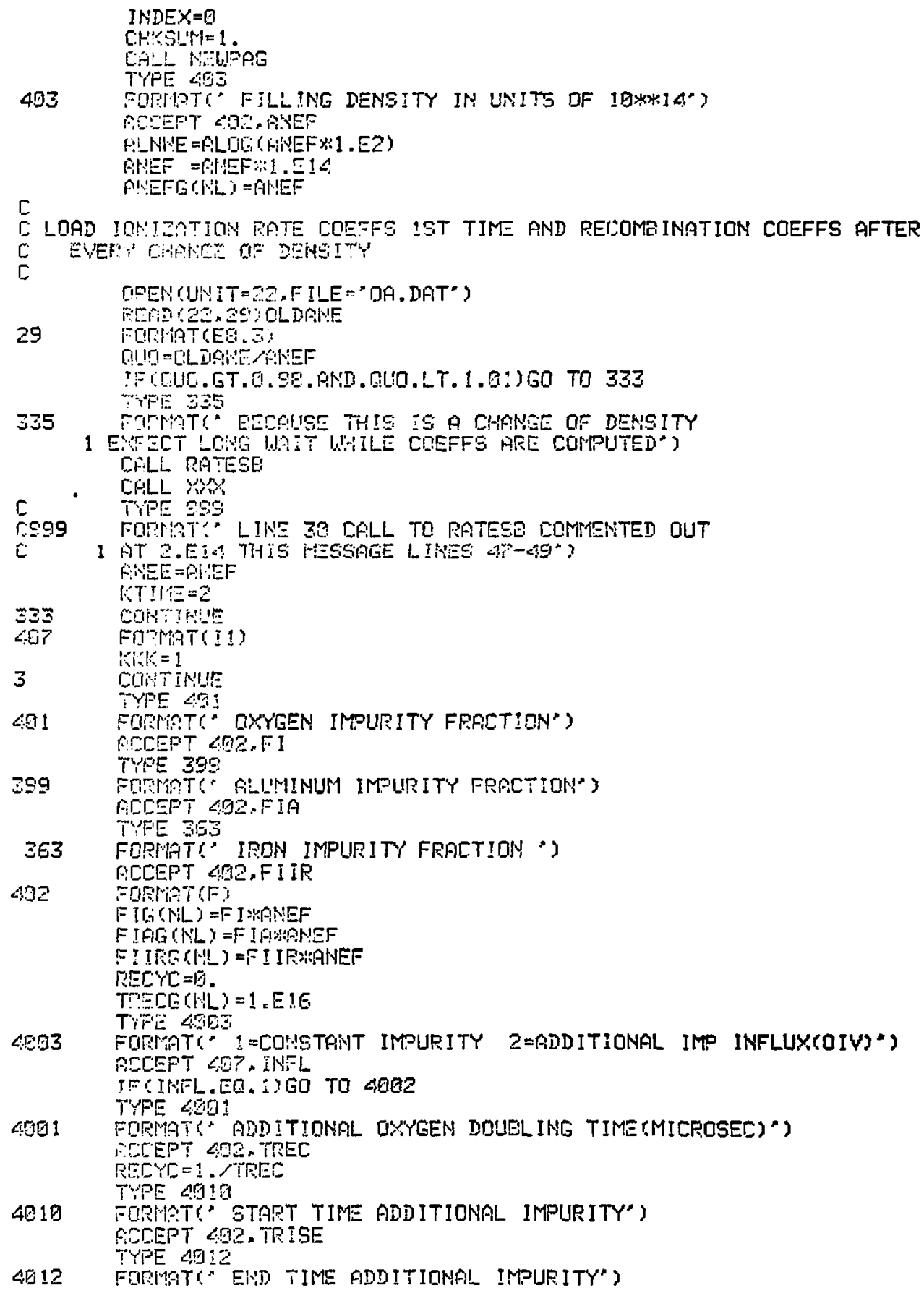




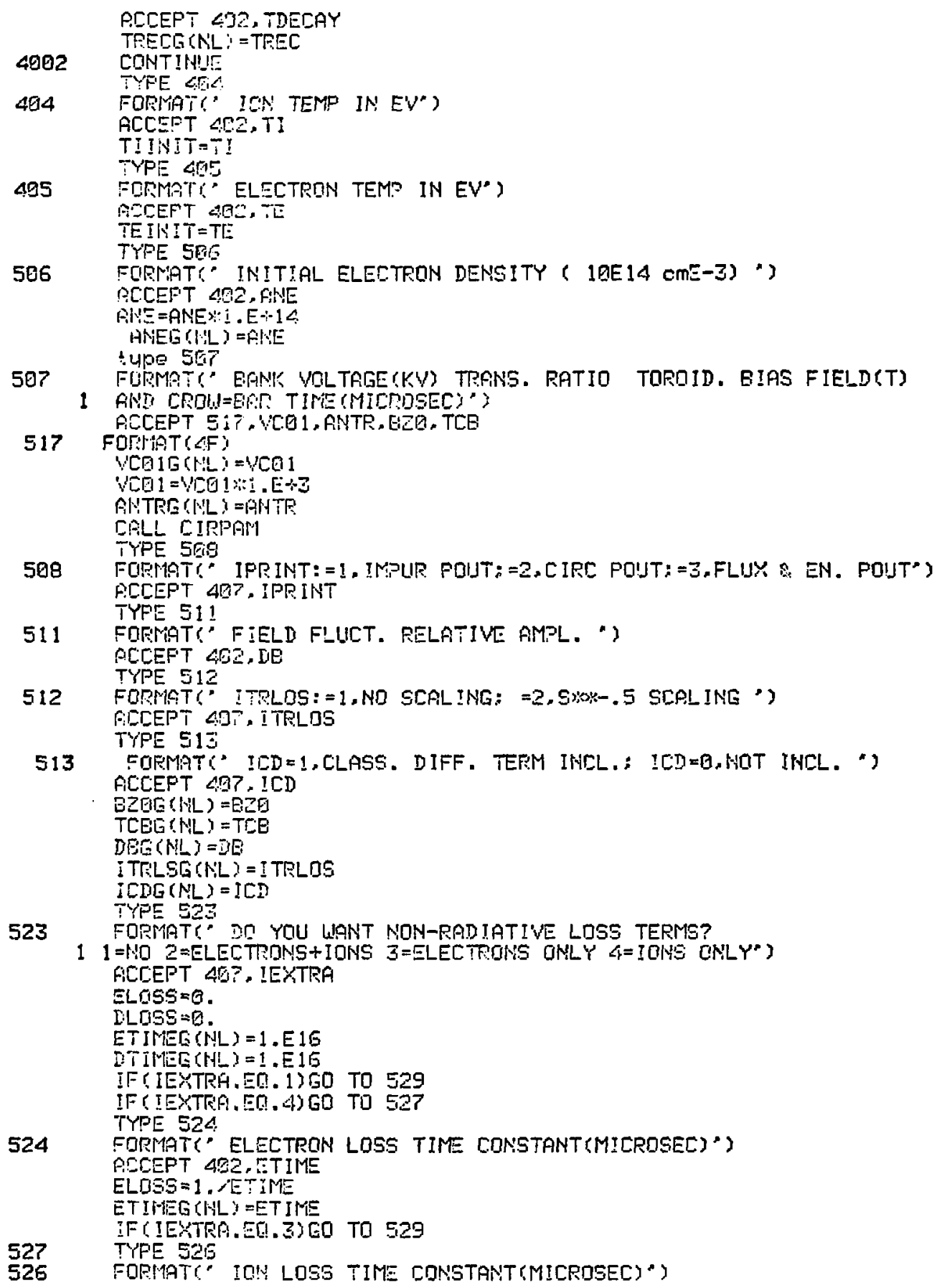




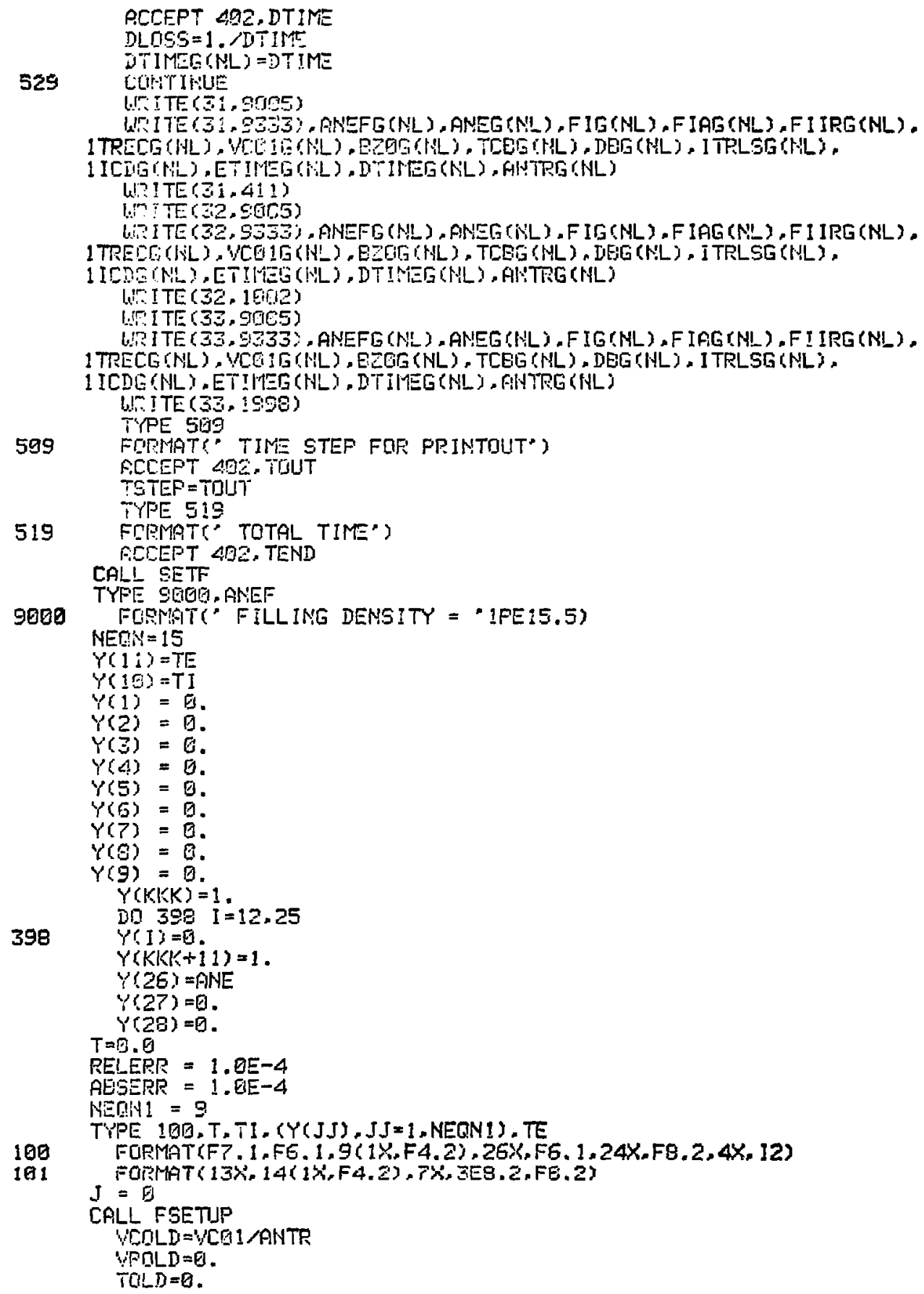




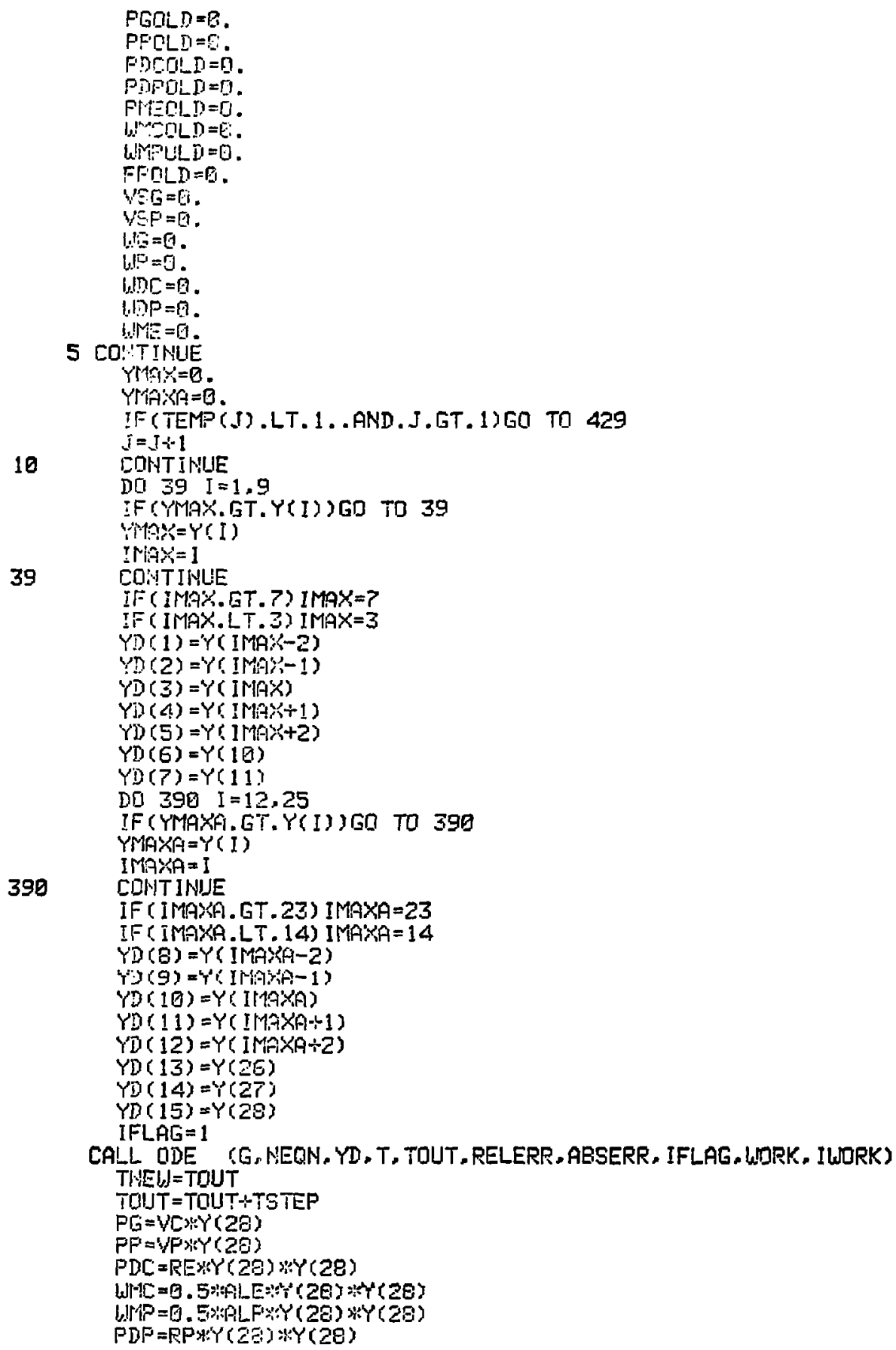




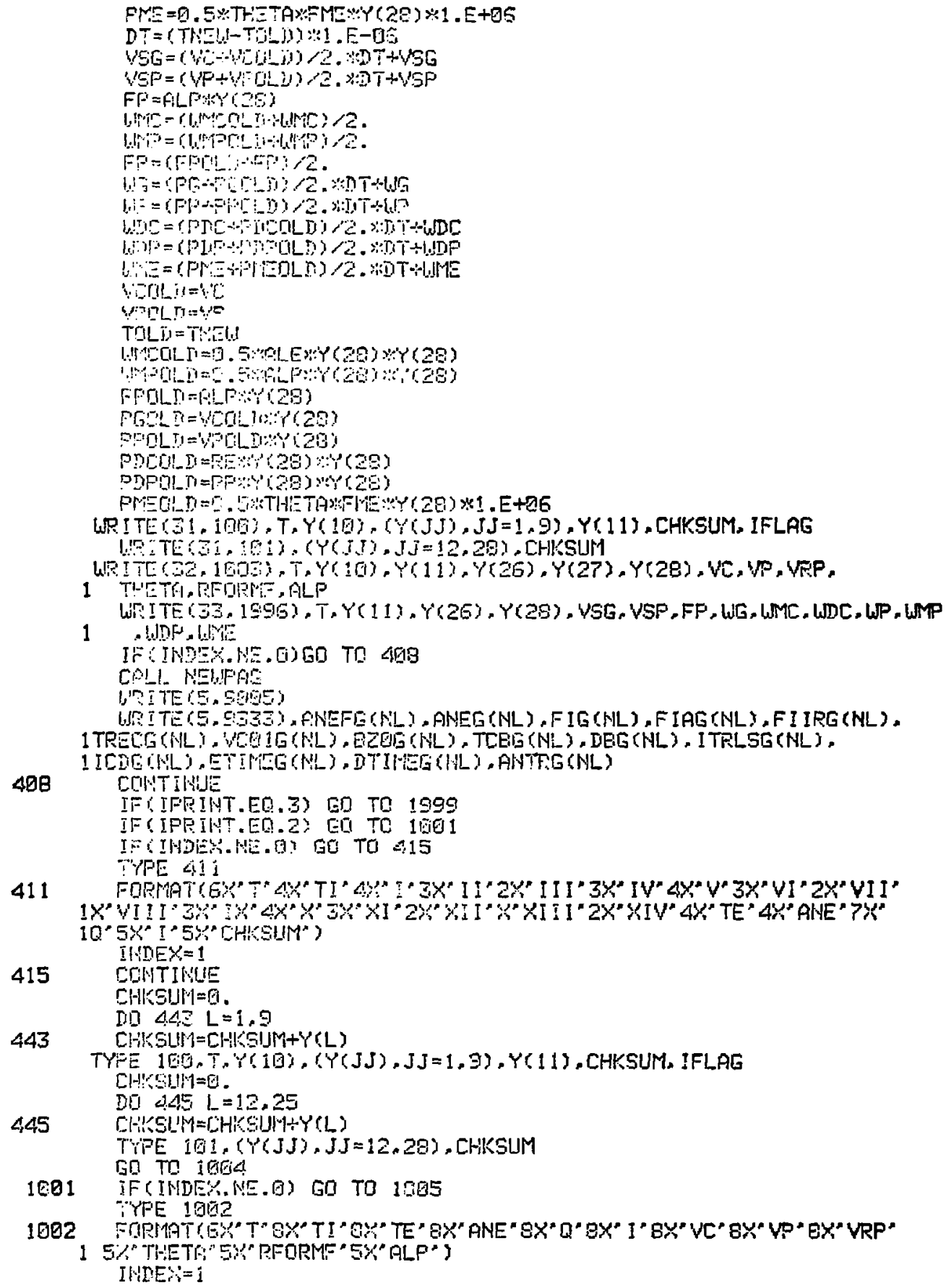




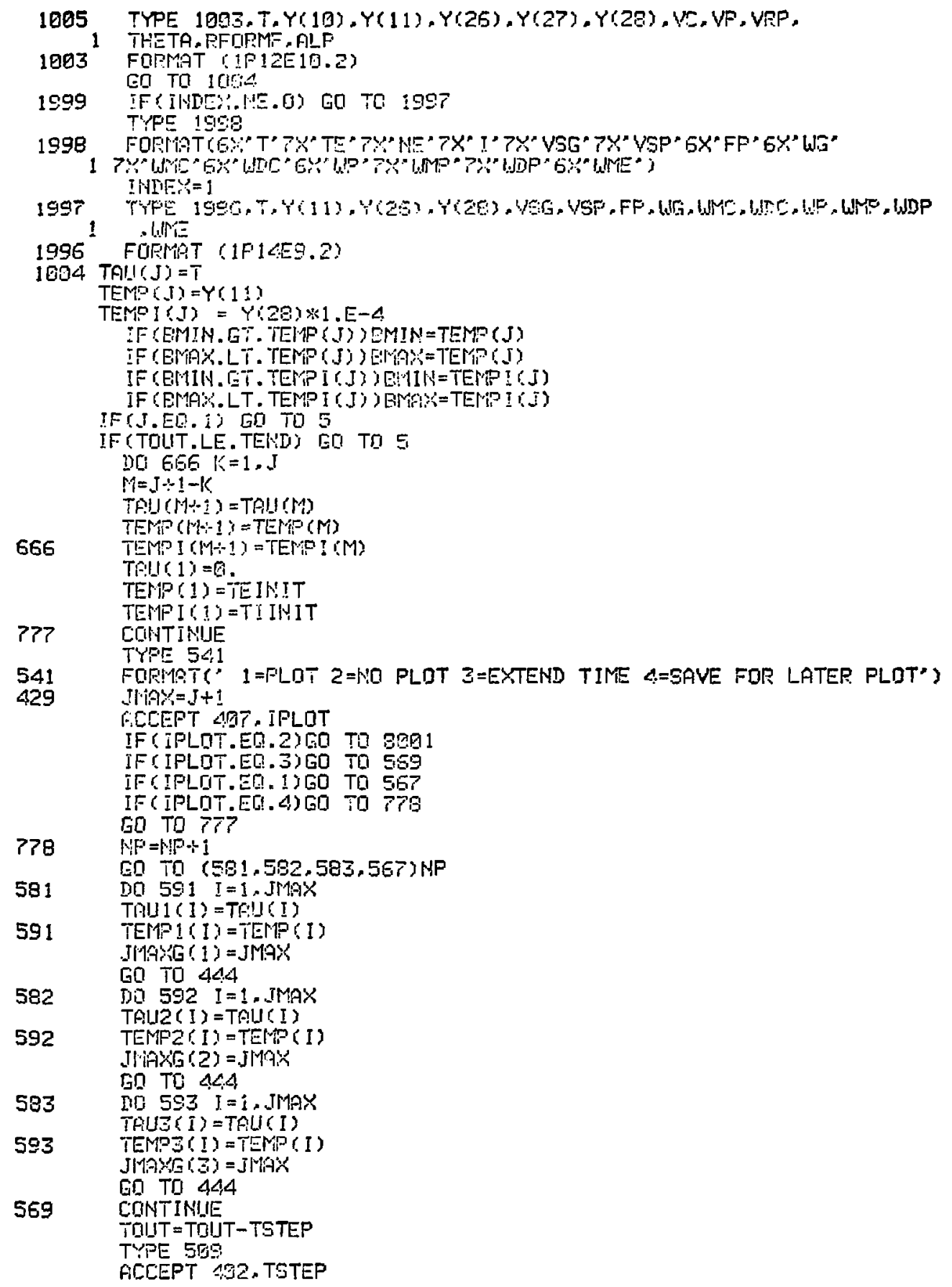




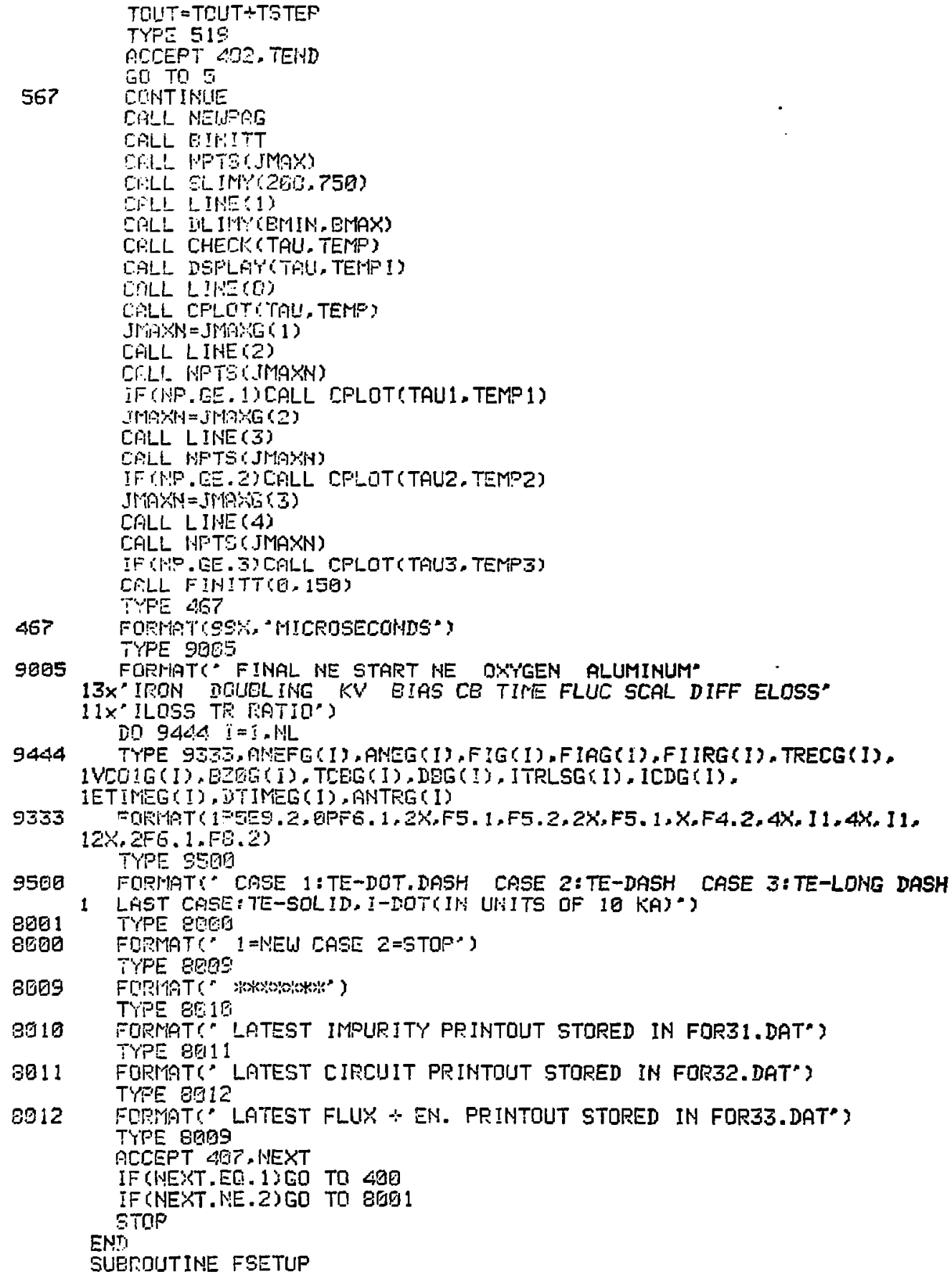




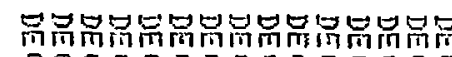

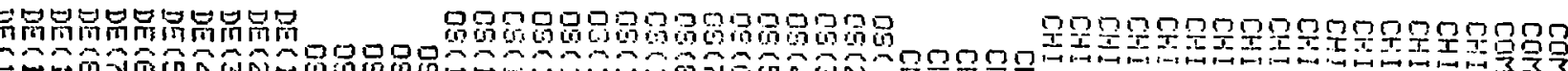

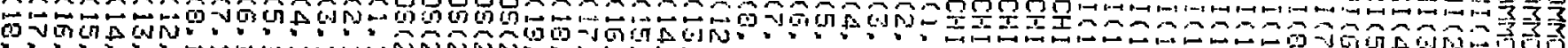

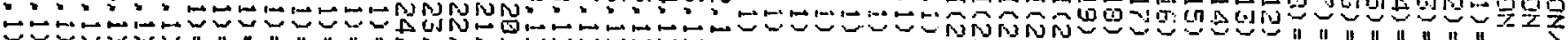
4 cos. - ocion จูก

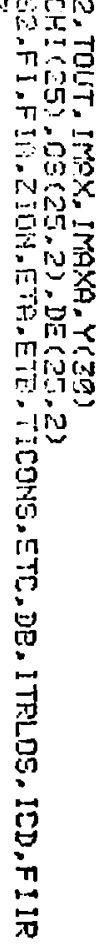


DE $(19.1)=33.22$

$D E(20.1)=2 r \cdot .23$

$\mathrm{DE}(2 i, 1)=20.58$

$\square \mathrm{C}(22,1)=22.47$

DE $(23.1)=1599$.

$D E(24.1)=1724$.

$09(i .2)=0.42$

$0.5(2.2)=6.365$

$05(3.2)=0.652$

$[5(\therefore .2)=0.455$

$05(5.2)=.55$

$05(5.2)=.262$

$0 \mathrm{D}(i-2)=0.0$

$0 S(8.2)=.0$

$0 S(12,2)=0.12$

$0 S(13.2)=2.7$

$05(14.2)=0.60$

$0 \Theta(15.2)=1] .48$

$[0(15,2)=.12$

$05(17.2)=.196$

$05(19.2)=1.2: 15$

$05(19.2)=1.056$

$05(20.2)=.591$

$0 S(21,2)=. E P G$

$05(22,2)=.354$

$05(23.2)=.75$

$05(24.2)=.42$

$D E(i, 2)=i \in .7$

$D E(2,2)=25.075$

IUE $(3,2)=39.37$

$D E(4,2)=51.98$

$D E(5,2)=72.22$

$D E(E, 2)=92.60$

$D E(?, 2)=5.5 i$.

Dะลㄴ $(0.2)=653$.

$D E(12,2)=4.62$

$D E(13.2)=7.34$

DE $(i 4.2)=6.66$

DE $(15.2)=95.6$

$\operatorname{DE}(i \in, 2)=44.3$

IEE $(17,2)=3 \Xi .8$

$D E(16,2)=159.6$

$\mathrm{DE}(19.2)=101.9$

$D E(20.2)=2014.5$

$\mathrm{DE}(21.2)=236.1$

$D E(22.2)=257.3$

DE $(23.2)=1599$.

DE $(24,2)=1724$.

C BRSED ON $P(D H M)=5.2 E 17 * J * * 2$ (KA CM**2) **2*E-6 ERGS/MICROSECOND

C USING COULOME LDG $=10$

$E T C=5.2 E-4$

$E T E=E T C \div 1 . E+14 * 19 . x 1 . E-06 / 1.6 E-12$

$P I=3.1415927$

$Y M E=9.1 E-28$

$X M I=3.34 E-24$

$E=4.9 i E-19$

$X L N L A=10$.

C TICOHS BFSED ON EO 9-6Q IN LONGMIRE IIITH LN TERM = 19 AND TIME IN

C MICROSECOIYDS. TEMP IN EV. MJLTIPLIER IN IOH-ELECTROH EXCHANGE TERM

C LOG TERM CORRECTED LATEP FDR IENS. TEMP VARIATIOH 
TICONS=4.EE-GMEQRT (2. $* P 1) * 2 . / 3 . * M-N L A \%$

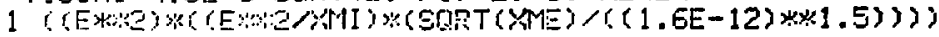

FE $\rightarrow U F C$

EISD

GUEROUTINE G(T, YD, YP

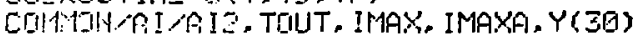

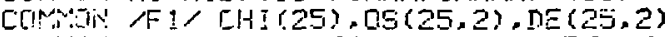

CONTI

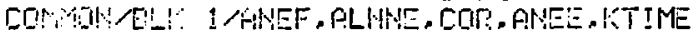

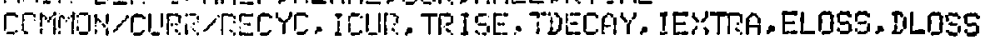

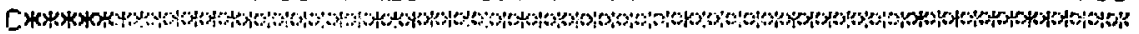

c

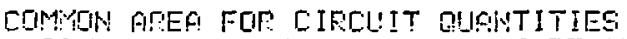

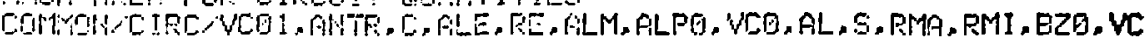

E

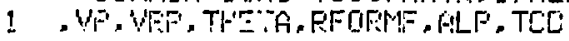

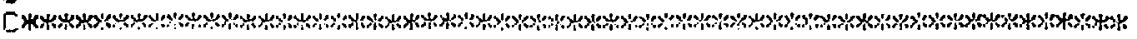

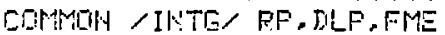

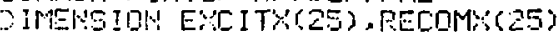

DIM

PEFI! MESTI

YEYYYYT?

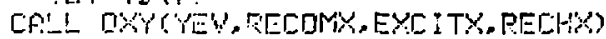

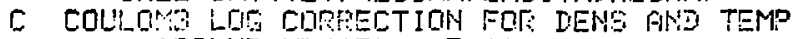

FICELIUE $=Y$ YI 1.3$) * 1$. E-16

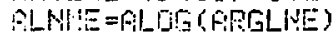

GINTE=ALOE(YOP(7)

COFT $=5.02-6.5 \% A L N N=+1.5 \times$ MLNTE

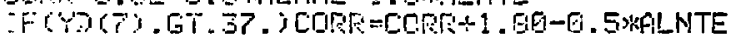

$\mathrm{COP}=\mathrm{CDPE}, \mathrm{ID}$.

Din $=1$

FF (MOK. I.T.3) IONE = IMAX-2

IF CPRK. BT. F) IONE $=5$

$\angle C N E A=12$

IF (MAYA. E- 14) IONEA =IMAXA-2

IF (IMXF. E - 23 ) IUNEA $=2 i$

ITLIDE = IONEG $1+1$

THPEA = IONEA- $\div 2$

IFOURA = IONEA+3

IFIMEA = ICNEPA+4

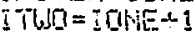

ITHFEE = IDNE $\div 2$

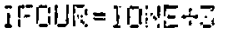

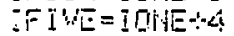

$5 I M=0$.

SLIO $=0$.

SUESUP $i=1$.

FIN $I=0$.

$20554 k=1,0$

SUBGUM $=5 U E S U M+Y(K+1) * K \% * 2 *=1$

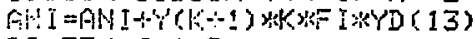

$554 \quad$ SLH=SUMH (K) *OS $(K, J) * E X P(-D E(K, J) / Y(11))$

I0 $5.55 k=12.24$

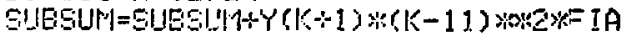

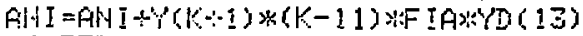

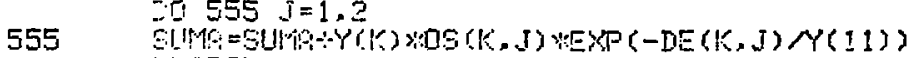

FL IE: 대 $=0$.

IFCFIIR.EG.G） CO TO 1111 
CALL P!FON(YD(T),FF,FZ,FZZ?

1111

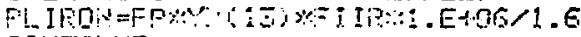

CrNTINL

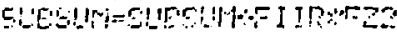

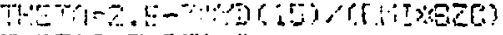

$T H E T A=T H A T H$.

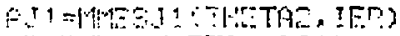

?

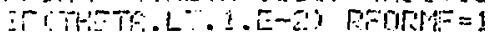

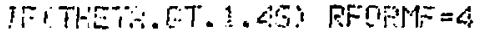

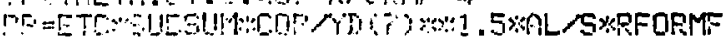

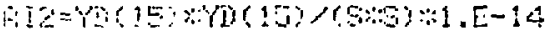

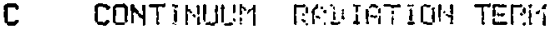

EPRE = YTSE

$D 9, \quad k=2.5$

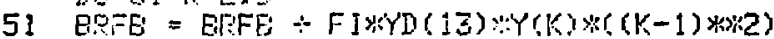

.0521015 .25

52

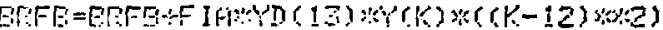

RFII $=7.6<5-2$ C

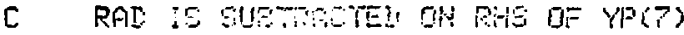

PHE I = YN (13) HAlli

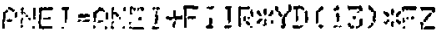

BDT? $1 \mathrm{TH}=\mathrm{C}$.

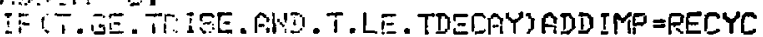

$Y P(G)=-T I C[D S W C D E$ W(D $(15) *(Y D(6)-Y D(7)) /(Y D(7) * * 1.5)$

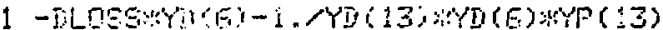

SP $(1)=-P$ NE I WY ( $)$ )

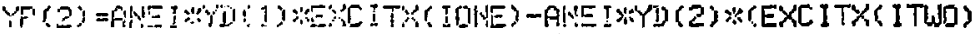

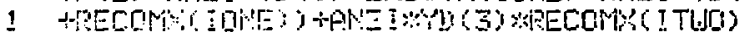

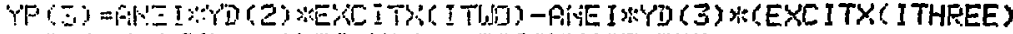

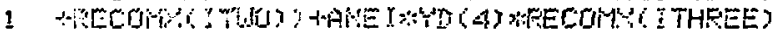

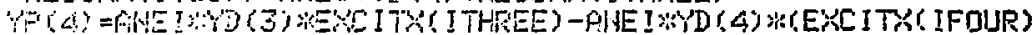

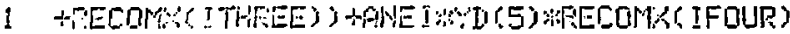

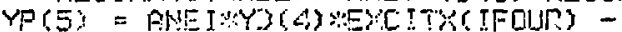

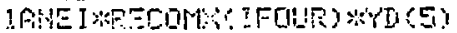

C MATLAHI FFITUE IS IN THE SECOND TERM

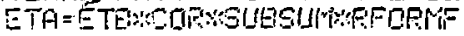

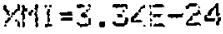

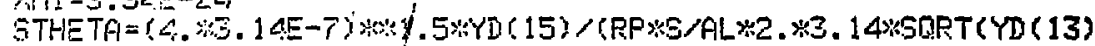

1 (N)

IF (ITELOE ER . 1) GO TR 1099

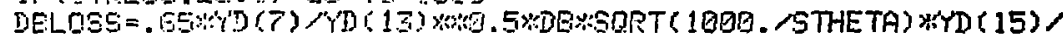

1 (EMTHETIS)

EO TI 1019

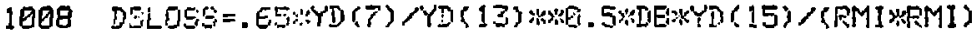

1009 COHTINLE

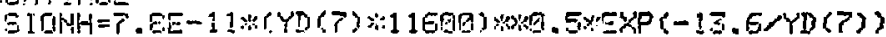

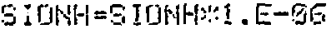

Big $=9$.

$P I P=0.0$.

Din $7>I=1.6$

$J=I$ TINE $-+T-1$

$K=I$ ONEA $\div$ I -1

$L=7+I$

PIIJ=PIOHYY I ) HEXEITX(J)*CHI (J)

77 CONTINHE

$P I D=P I D * W=I: P(13)$

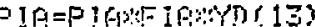

$Y P(7)=(E T A *(12 /(A N E I * Y D(7) \times(* 1.5)-(A N E 135 / 1.6 E-12) *$ 


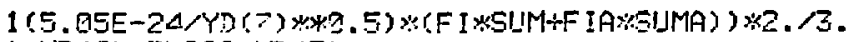
$1-Y P(6)-E L Q S E * Y O(T)$

$1-F A D$

-1 . PANE I NTS (P) KYP (13)

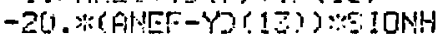

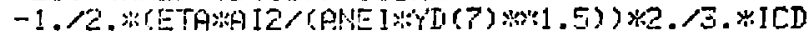

$-D E-D S S$

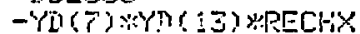

-FIO-PIA-FLIPOH

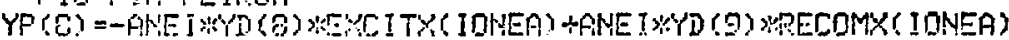

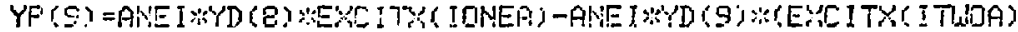

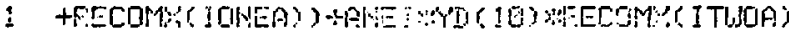

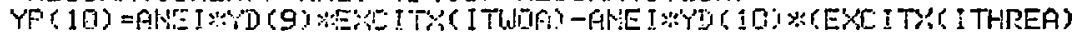

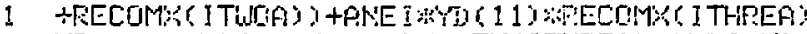

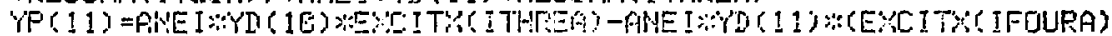

1 TRECOMK(ITHREA) ) +FHE I

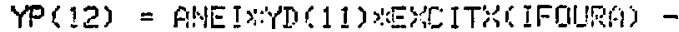

1RNE THRECOIY (IFOURA) WMY I 2 )

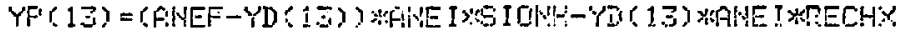

IF (THETA.IT.Q.4) F:LP=ALFGXX.

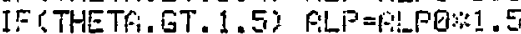

$D L P=0$.

IF(TTETA.EE.Q. 4. FND.THETA.LE. 1.E)EO TO 777

777 AIS=3.14\%?THETP-0.4)*.625

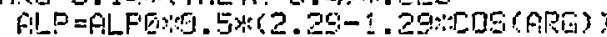

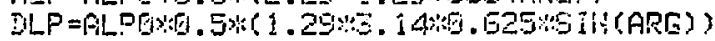

778 CONTIRHE

$\checkmark C=V C O-V D(1 \angle) / C$

VF $=(A L P+T H E T A \% D L P) * Y P(15) * 1 . E+A 5-R P * Y D(15)$

FME =DLP世Y $(15)$

VFP=FPWY

IF(VE.GT.E. AAND.T.LT.TCE) GO TO 111

$V C=\bar{E}$.

RE $1=147 . E-616$

ALE $1=4 . E-D S$

GINTR2 = PNTTRYANTR

RE =RE 1 A A N MTR2

111 COLYTINLIE

ALE $=$ GLIF I $/$ ANTR2

$Y P(10)=1 . E-6 \times Y D(15)$

$Y(15 j)=1 . E-E$ (ALE-FLP+THETA*DLP) $*(V C-(R E+R P) * Y D(15))$

$Y(I M(M X-Z)=Y D(1)$

$Y(I M A X-1)=Y D(2)$

$Y(I M A X)=Y D(3)$

$Y(\operatorname{IMAX} \div-1)=Y D(4)$

$Y(I M A X+2)=Y D(5)$

$Y(I M A X A-2)=4 T(Z)$

$Y($ IMAX $X A-1)=Y(3)$

$Y($ IMAXG $)=Y D(10)$

$Y(1 M A) X A+1)=Y D(11)$

Y Ir I A X A $* 2)=Y D(12)$

$Y(10)=Y D(G)$

$Y(11)=Y D(T)$

$Y(26)=Y D(13)$

$Y(27)=Y D(14)$

$Y(2 \beta)=Y D(15)$

RETIENY

END

SUERDUTINE SETF 


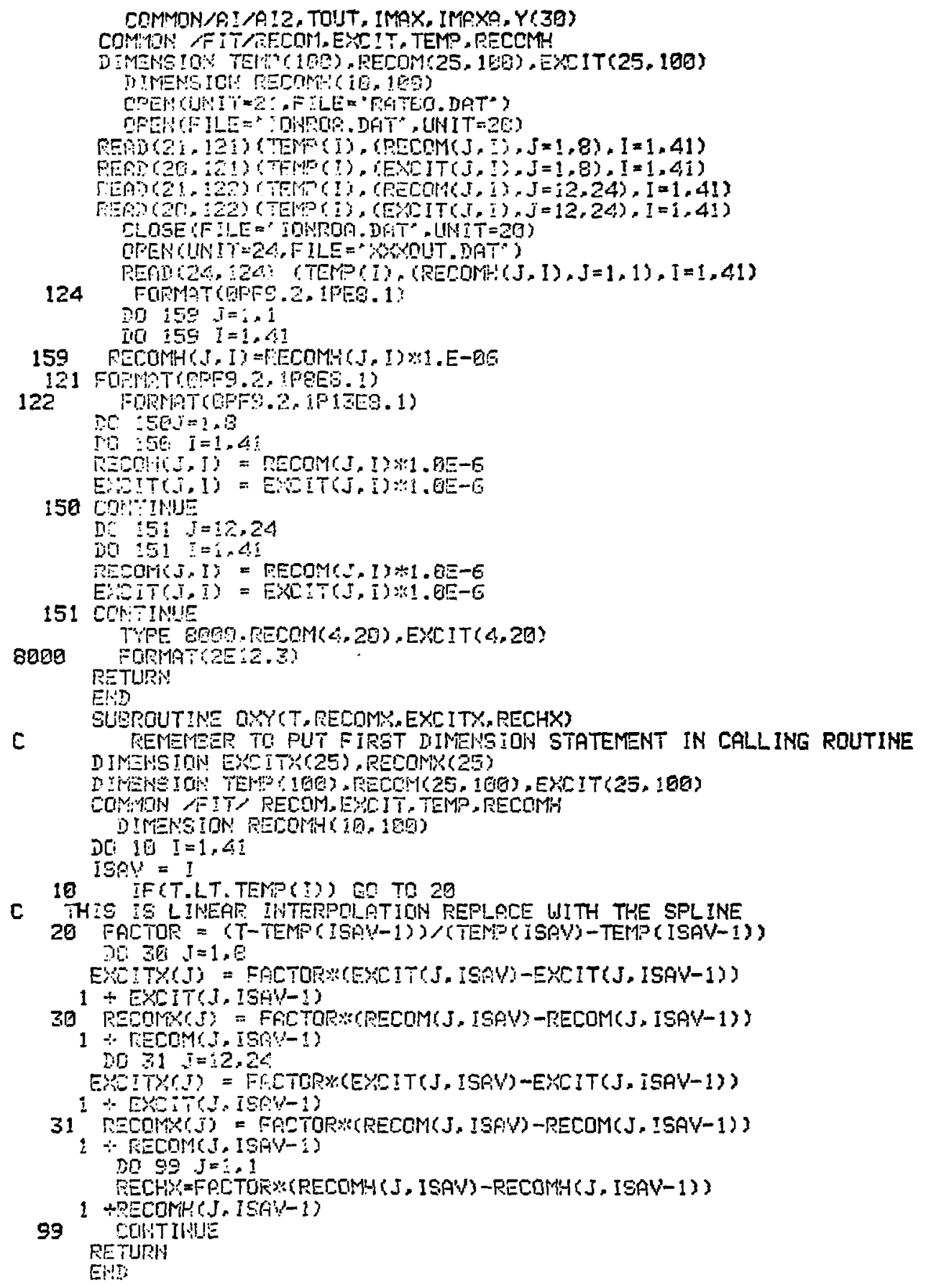


SUBROUTINE CIRPAM

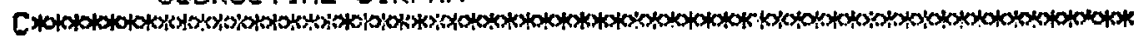

c

COMTON AREA FOR CIRCUIT QUANTITIES

COMDON IRE NCO

C

1 , W. VRP, THETA, RFORMF, ALP, TCE

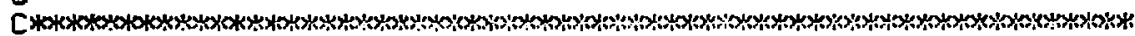

$C i=30600 . E-05$

QIE $1=0.0975-6 G$

RE $1=1.50 \mathrm{TE}-\mathrm{BO}$

ALM $=10 . E-6 G$

$F M A=1.14$

FACTOR $=$ !

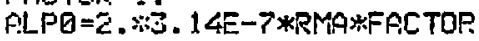

$\mathrm{RI} I \mathrm{I}=.2$

P.L $=2 . * \overline{3} .14 \% \mathrm{MMA}$

$S=3.14 \% R M I \times P M I$

C CIRCUIT PARAMETERS ARE TRGNSFORMED TD THE SECANDARY

FINTP2 = FNTR WFNTR

$C=C 1 * A M ! T R 2$

VCE $=V \mathrm{CQ} 1$ PANTR

FILE $=$ PLLE $1 /$ GIVTR2

$R E=P E 1 / P I N T R 2$

RETUIN

END

SUEROUTINE AIROH (TEV,FP,FZ,FZZ)

TISEV $=T E V: 1 . E-3$

IF(TIEV.LT.Z.E-2) EO TO 1

IF(TKEV.GT.20.) GO TO 2

IF (TKEV.GT.2.E-2.AND.TKEV.LT.2.E-1) GO TO 3

IFCTKEV.GT.2.E-1.ANI.TKEV.LT.2.) G0 TO 4

$A G=-16 \cdot 71042$

$01=-16.46143$

$A_{2}=37.66238$

$A 3=-39.4,4060$

$A 4.19 .18529$

$A 5=-3.509238$

$\theta 0=14.78150$

$B 1=65,45311$

$B 2=-199 \cdot 1202$

$B 3=265.3904$

$B 4=-163.1423$

$\mathrm{B} 5=37.70926$

$C E=110.1937$

$C 1=34.4 .816$

$C_{2}=-9953.434$

$\mathrm{C} 3=13280.63$

$C \Delta=-8173.660$

$C 5=1691.447$

GD TO 5

$4 \quad A(1)=-10.34973$

$A 1=-1.252026$

$A 2=-7.533115$

$A \bar{B}=-3.289693$

$A 4=20.66739$

$75=28.310249$

$E V=19.59496$

$E_{1}=19.97052$

$E 2=9.593373$ 


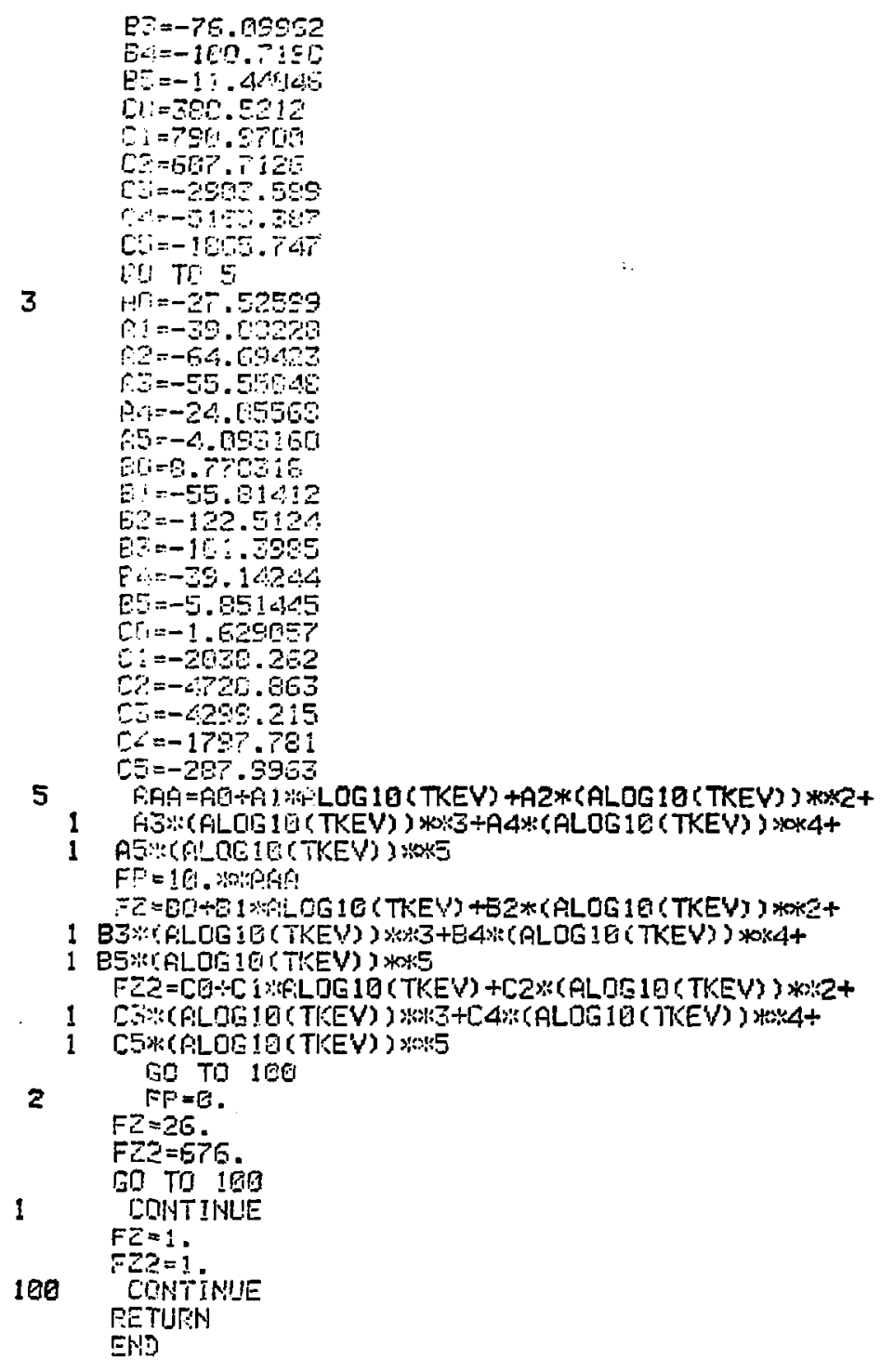


APPENDIX III

INPUT DIALOG

FILLING DENSITY IN UNITS OF 10XK14

3.5

OXYGEN IMPLRITY FRACTION

0.0

ALUMINUM IMPURTTY FRACTION

e.0

IRON IMPURITY FRACTION

0.8

I-CONSTANT IMPURITY 2-ADDITIONAL IMP INFLUXIOIUI

ION TEMP IN EU

ELLCTRON: TEMP IN EV

INITIAL ELECTRON DENSITY ( $10 E 14$ CNE-3)

0.035

BANK VOLTAGE(KU) TRANS. RATIU TOROID. BIAS FIELD(T) AND CROU-BAR TIME(MICROSEC)

8 ...25,.25, 100 .

:PRiNTi-1, IMPUR POUT,-Z,CIRC POUT,-3,FLUX \& EN. POUT

i

F:ELD FLUCT. RELATIUE AMPL.

0.3

1TALOSI-1, NO SCALING, -2,S\$I-.5 SCALIMG

¿CO1,CLASS. DIFF. TEAM INCL., ICD-Q, MOT INCL.

DO YOU WANT NON-RADIATIUE LOSS TERMS? I-NO Z-ELECTRONS+IONS 3-ELECTRONS ONLY A.IONS OMLY IIME STEP FOR PRINTOUT

total TIME

10 
ro ru ro no no no no

×

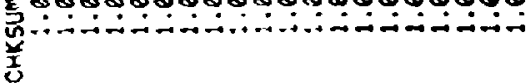

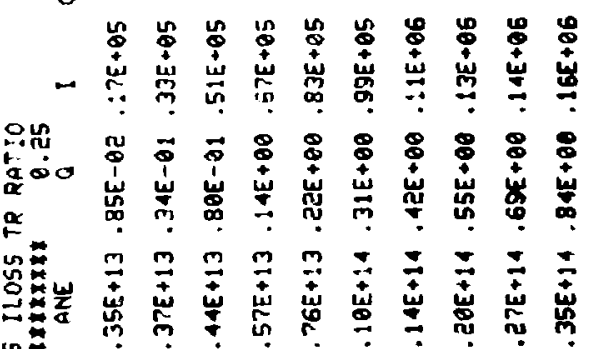

足

告

㫐..

1298\% $898 \% 8 \%$

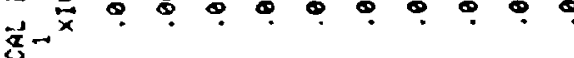

世

38

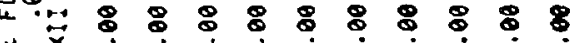
Le

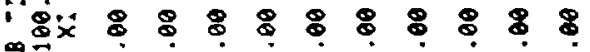
为

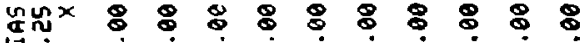
$\infty \infty^{+}$

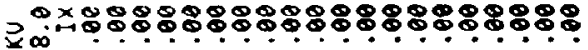

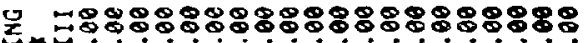
$\rightarrow=$

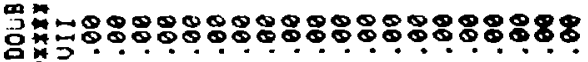
8

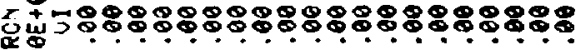

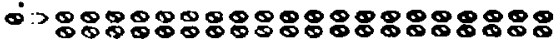

ร马) 는 10000000000000000000

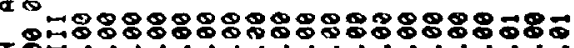
z

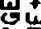

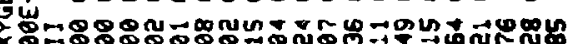

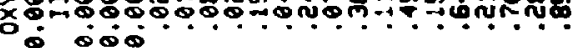
쑨

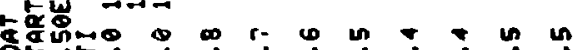

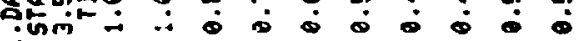
Mut

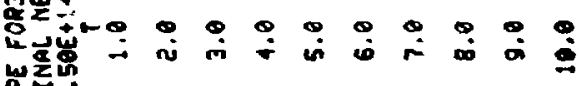

$\sum^{2} m$

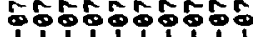
a immimmimin:

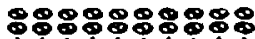
On

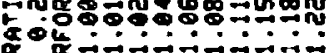
a

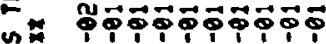
ઝ ब $\Rightarrow$ * بmómon un 14 0

ngugumyan $+4898 \%$

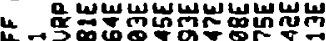
$4050 \%$ o

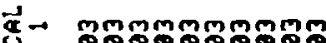
ज $90 \%$

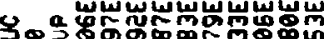
马gذ 4. busivivisirio \%o -8

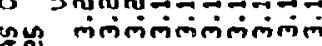
\&

क क

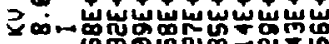

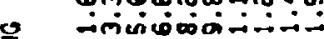
눈 뭉

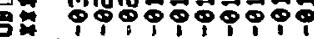

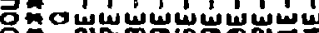
\& 8 ômm

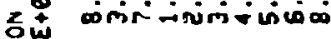

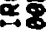

mincummmm Si $F+7+7+7+7+$ 5 iy misinininim 동

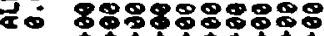

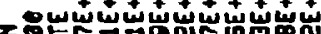
1.

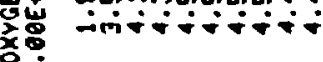

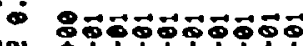
In

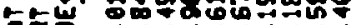

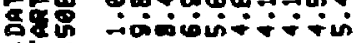
in

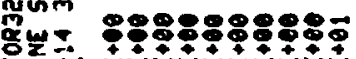

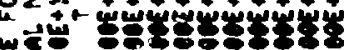
重究 $\lim _{i} m$
$000000 \mathrm{~m}$ ru

여연?

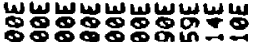

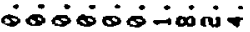

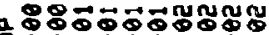

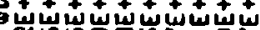
XOPMM

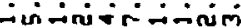
$\rightarrow$ Mummmmm 는 $90090900 \%$

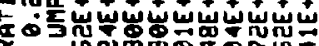
o vimi-ininim:

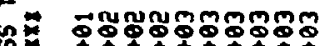
을 -

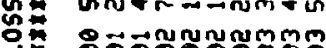
In 0009000000

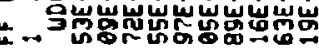
$\rightarrow$ micising

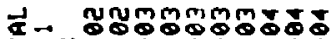

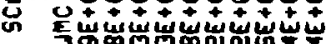

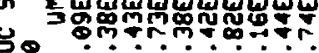
تأ 4.

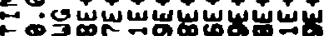
- $8=9670 \% 5+5=$ 3 ninitióicinin

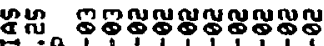

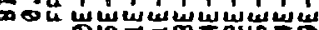

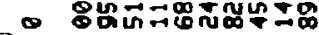
วெ ம்

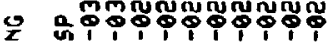
* - miscicumitivi

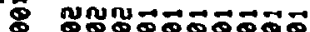
$2+01,19,1,1,1$

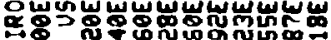

- mi்íininim

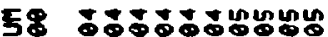

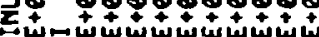

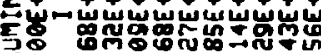

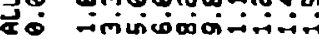
z 8 curunummmm

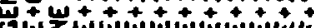

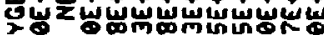
วक in - mintiñ-inim 닐 8989898989 - + oxu cuntronent min initi-itit ợ

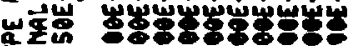
Lim inimisirió 